\title{
EMPOWER-1.0: an Efficient Model of Planktonic ecOsystems WrittEn in $\mathbf{R}$
}

\author{
T. R. Anderson ${ }^{1}$, W. C. Gentleman ${ }^{2}$, and A. Yool ${ }^{1}$ \\ ${ }^{1}$ National Oceanography Centre, University of Southampton, Waterfront Campus, European Way, \\ Southampton SO14 3ZH, UK \\ ${ }^{2}$ Department of Engineering Mathematics, Dalhousie University, 5269 Morris St., Halifax, Nova Scotia, B3H 4R2, Canada
}

Correspondence to: T. R. Anderson (tra@noc.ac.uk)

Received: 10 November 2014 - Published in Geosci. Model Dev. Discuss.: 5 January 2015

Revised: 6 May 2015 - Accepted: 3 July 2015 - Published: 24 July 2015

\begin{abstract}
Modelling marine ecosystems requires insight and judgement when it comes to deciding upon appropriate model structure, equations and parameterisation. Many processes are relatively poorly understood and tough decisions must be made as to how to mathematically simplify the real world. Here, we present an efficient plankton modelling testbed, EMPOWER-1.0 (Efficient Model of Planktonic ecOsystems WrittEn in R), coded in the freely available language R. The testbed uses simple two-layer "slab" physics whereby a seasonally varying mixed layer which contains the planktonic marine ecosystem is positioned above a deep layer that contains only nutrient. As such, EMPOWER-1.0 provides a readily available and easy to use tool for evaluating model structure, formulations and parameterisation. The code is transparent and modular such that modifications and changes to model formulation are easily implemented allowing users to investigate and familiarise themselves with the inner workings of their models. It can be used either for preliminary model testing to set the stage for further work, e.g. coupling the ecosystem model to 1-D or 3D physics, or for undertaking front line research in its own right. EMPOWER-1.0 also serves as an ideal teaching tool. In order to demonstrate the utility of EMPOWER-1.0, we implemented a simple nutrient-phytoplankton-zooplanktondetritus (NPZD) ecosystem model and carried out both a parameter tuning exercise and structural sensitivity analysis. Parameter tuning was demonstrated for four contrasting ocean sites, focusing on station BIOTRANS in the North Atlantic $\left(47^{\circ} \mathrm{N}, 20^{\circ} \mathrm{W}\right)$, highlighting both the utility of undertaking a planned sensitivity analysis for this purpose, yet also the subjectivity which nevertheless surrounds the choice of
\end{abstract}

which parameters to tune. Structural sensitivity tests were then performed comparing different equations for calculating daily depth-integrated photosynthesis, as well as mortality terms for both phytoplankton and zooplankton. Regarding the calculation of daily photosynthesis, for example, results indicated that the model was relatively insensitive to the choice of photosynthesis-irradiance curve, but markedly sensitive to the method of calculating light attenuation in the water column. The work highlights the utility of EMPOWER1.0 as a means of comprehending, diagnosing and formulating equations for the dynamics of marine ecosystems.

\section{Introduction}

Ecosystem models are ubiquitous in marine science today; they are used to study a range of compelling topics including ocean biogeochemistry and its response to changing climate, end-to-end links from physics to fish and associated trophic cascades, the impact of pollution on the formation of harmful algal blooms, etc. (e.g. Steele, 2012; Gilbert et al., 2014; Holt et al., 2014; Kwiatkowski et al., 2014). Models have become progressively elaborated in recent years, a consequence of both superior computing power and an expanding knowledge base from field studies and laboratory experiments. All manner of models have appeared in the published literature varying in terms of structure, equations and parameterisation. Anderson et al. (2014), for example, commented on the "enormous" diversity seen in chosen formulations for dissolved organic matter (DOM) in the current generation of marine ecosystem models and asked whether reliable sim- 
ulations can be expected given this diversity. This question applies not just to modelling DOM, but also to most processes and components considered in modern marine ecosystem modelling (Fulton et al., 2003a; Anderson et al., 2010, 2013).

A certain amount of variability among models is to be expected because of differing objectives among modelling studies. A distinction can, for example, be made between models designed primarily for improving understanding of system dynamics, as opposed to those for out-and-out prediction (Anderson, 2010). Ultimately, however, much of the variability seen in model structure and equations is an outcome of personal choice on the part of the practitioner. Indeed, the art of modelling is in making decisions regarding model structure, parameters, design of simulations, types of output analysis, etc. The underlying root of this diversity and seeming subjectivity is that, despite a wealth of available data, many processes in marine ecosystems are not easy to characterise mathematically. Modellers therefore need to consider how this uncertainty affects their results and use it to inform how best to construct and parameterise their models for chosen applications. Sensitivity analysis and model validation are the obvious means to address model uncertainty, as well as model intercomparison studies. There is however an additional problem, namely that ocean biology is inextricably linked to physics and both incur modelling error. An appropriate physical framework must be selected that adequately represents mixing, advection and the seasonal changes in the depth of the upper mixed layer. Understandably, 1- or 3-D physical frameworks are the usual choice, given the realism thus provided. But this increased dimensionality (or spatial resolution) comes at a price. They require expertise and time to set up, sufficient computational resources for running and storage of output and, last but not least, analysis of the frequently copious output into coherent results. These constraints serve to limit the extent to which modellers can and do carry out extensive diagnosis and testing of their models including sensitivity analysis and validation.

In the early days of marine ecosystem modelling, it was necessary to resort to simple empirical approaches to deal with physics given the limited power of computers at the time. The so-called zero-dimensional "slab" models that came to the fore were the cornerstone of their discipline in the mid 20th century. Slab models have a simple physical structure consisting of two vertical layers. The depth of the upper (mixed) layer, which can vary seasonally, was determined empirically from observations of vertical profiles of temperature or density. Containing the pelagic marine ecosystem, the upper layer was positioned above an essentially implicit (in that it is unchanging) bottom layer that contains a (typically fixed) nutrient concentration. Such slab models can be run quickly and straightforwardly, enabling both a multitude of runs and ease of analysing results.

Despite the simplicity of the two-layer slab physics, these models are sufficiently well formulated to permit realistic and insightful simulations of marine ecosystems (e.g. Evans and Parslow, 1985; Fasham et al., 1990). Indeed, looking back at the history of marine ecosystem modelling, it is remarkable how simple models allowed so much progress to be made, notably by pioneers such as Gordon Riley, John Steele and Mike Fasham (Gentleman, 2002; Anderson and Gentleman, 2012). We admire these individuals when it came to encapsulating the complexity of the real world with mathematical equations. They necessarily had to think deeply about their models because they had to build them from scratch as, in most instances, established relationships for processes such as photosynthesis, grazing and mortality could not be borrowed from elsewhere. A key aspect of their success, we submit, is that they experimented extensively with their models, trying out different formulations and parameterisations in order to see the effect on model predictions (e.g. Anderson and Gentleman, 2012). It is this preparation that served them so well, allowing them to set up meaningful simulations from which they could so effectively draw conclusions and make progress in their field of study.

The need for preparation in terms of exploring sensitivity to ecosystem model formulations and parameterisation is no less in the modern era, indeed it is arguably greater given our deeper knowledge of the marine biota and a correspondingly larger multitude of mathematical formulations to choose from. We propose that modellers can benefit from extensively "playing with" and testing their models and that the use of simple slab physics is an obvious choice in this regard, at least for ocean locations where the bulk of the biological activity occurs in the surface mixed layer. Experimentation of this kind may then be used to set the stage for the "serious" model runs that may follow, e.g. in 1-D or 3-D, although it is also entirely possible to undertake successful studies using only slab physics models. In addition, because they are straightforward to understand and do not require powerful computing resources to run, models that incorporate simple slab physics are ideal for use in teaching future generations of marine scientists about ecological structure and function.

Here, we present a slab a.k.a. zero-dimensional, and hence computationally efficient, plankton ecosystem testbed, coded in the freely available R environment, EMPOWER-1.0 : Efficient Model of Planktonic ecOsystems WrittEn in R. Our aim is to provide EMPOWER-1.0 for general use and to demonstrate how it can readily and easily be used both to study ecosystem dynamics at a range of ocean sites and to assess the pros and cons of different model choices for best representing and analysing the ecosystems in question. EMPOWER's code is structured in a modular way to ensure maximum ease of adjusting parameters and formulations and, indeed, the inclusion of entirely new marine ecosystem compartments, processes and associated outputs as required. Here, we demonstrate the use of EMPOWER-1.0 in combination with a simple illustrative nutrient-phytoplanktonzooplankton-detritus (NPZD) model. It should be noted, however, that EMPOWER-1.0 can be used to test and ex- 
amine the performance of simple and complex models alike. Our choice of a simple ecosystem model is motivated by the fact that simple models are conceptually straightforward as well as being easy to set up and analyse. This study is structured as follows. First, a brief history of slab models in marine science is presented to illustrate the origin and utility of these models as research tools in marine science. The NPZD model is then described and implemented within EMPOWER. The utility of EMPOWER as a testbed for undertaking model parameterisation is next demonstrated by a parameter adjustment exercise, specifically the fitting of the NPZD model to observed seasonal cycles of chlorophyll and nutrients at each of four stations in diverse regions of the world ocean. The sensitivity analysis is then extended to model equations with a comparison of the performance of different equations for calculating, first, daily depth-integrated photosynthesis and, second, phytoplankton and zooplankton mortality. Finally, the utility of slab models is discussed in context of ongoing contemporary marine ecosystem modelling research.

\section{Slab models: from pioneering studies to the present day}

In this section, we provide a history of slab modelling which serves as an introduction to how these models are constructed, as well as to demonstrate that, despite their simplicity, the simulations these models generate can be meaningful and realistic. Models provide the theoretical basis for our understanding of the dynamics of marine ecosystems. One of the first applications of theory in biological oceanography occurred around 80 years ago when scientists were interested in the mechanisms driving the spring phytoplankton bloom that is characteristic of many marine systems. The basic theory as we know it today, whereby bloom initiation occurs as the water column stratifies, was proposed in the early 1930s by Haaken H. Gran, a Norwegian botanist (Gran, 1932; Gran and Braarud, 1935). Mathematical testing of this proposal was essential in order to establish quantitative merit, given the dynamic interplay between bottom-up controls on phytoplankton via light and nutrients versus topdown control by grazing. Following on from initial work by Fleming (1939), it was Gordon Riley, a biological oceanographer based at the Bingham Oceanographic Laboratory in the northeastern USA, who constructed a model of seasonal phytoplankton dynamics for Georges Bank, a raised plateau off the coast of New England, northeast USA (Riley, 1946), a remarkable achievement at the time (Anderson and Gentleman, 2012). The model had a single differential equation for the rate of change of phytoplankton biomass, expressed with terms for photosynthesis, respiration and grazing. Using a photosynthesis-irradiance $(P-I)$ curve based on his own shipboard experiments, Riley developed a formula for daily depth-averaged photosynthesis in the mixed layer that
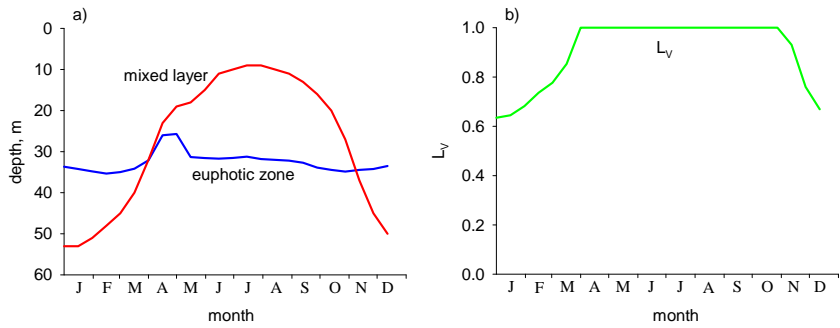

Figure 1. Forcing used by Riley (1946) in his model of George's Bank: (a) depths of euphotic zone and mixed layer; (b) diminution in photosynthesis due to light limitation $\left(L_{V}\right)$.

was derived from observed seasonal irradiance at the ocean surface as calculated by atmospheric transmission by Kimball (1928), measured light attenuation coefficients and a nutrient limitation term. The seasonal cycle of mixed layer depth (MLD) was imposed empirically, with calculated photosynthesis in the euphotic zone being diminished accordingly when MLD exceeded that of the euphotic zone (Fig. 1). Temperature was considered to affect net primary production via regulation of respiration. Despite its simplicity, in both biology and physics, Riley's model successfully reproduced the spring plankton bloom at Georges Bank, highlighting the subtle interplay between growth and grazing in controlling plankton stocks.

Although Riley's model considered depth-averaged photosynthesis over the mixed layer, it could not be described as a slab model per se because it did not account for fluxes of material across the pycnocline. It was John Steele, a mathematical marine biologist from Scotland, who took the next step by experimenting with a dynamic ecosystem embedded within multi-layer models (e.g. Steele, 1956), arguably a coarser version of what is done today in the more complex 1-D models. Steele's experience with this model led him to realise that much of the net effect of vertical gradients could be captured with just a few layers, and he further simplified the physics to a two-layer sea in his study of the plankton in the North Sea (Steele, 1958). The resulting NPZ ecosystem was confined to the upper layer with a lower layer that contained only nutrient, in fixed concentration. Inputs of nutrients to the surface layer occurred due to mixing, balanced by export via phytoplankton sinking and mixing (Fig. 2). Steele had thus constructed the first slab model of its kind although with this, as well as his later models including those in his seminal work The Structure of $\mathrm{Ma}$ rine Ecosystems (Steele, 1974), he used a fixed, rather than seasonally varying, mixed layer depth. Applying the model to study the plankton of Fladen Ground and other regions in the northern North Sea, Steele demonstrated good agreement between the model and estimates of production from observations. Through work such as this, Steele emphasised that it is simplification that allows us to most easily address the controlling factors in marine ecosystems. One of Steele's 


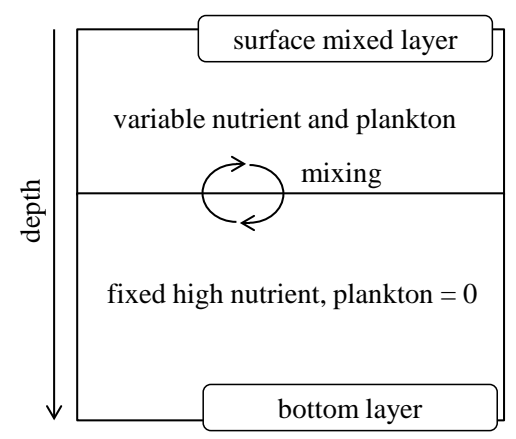

Figure 2. Two-layer slab physics framework (adapted from Steele, 1974).

best-remembered findings, demonstrated again using simple models, is that the form of the zooplankton closure term has important consequences for ecosystem dynamics and export flux (Steele and Henderson, 1992). This finding remains relevant to modellers today and, indeed, we will examine model sensitivity to zooplankton mortality in Sect. 4.4.

It was Geoff Evans and John Parslow who would make the next major advance in the development of slab models with their "model of annual plankton cycles" (Evans and Parslow, 1985). Following Steele, they opted for an NPZ ecosystem embedded within the same two-layer framework with the marine ecosystem restricted to the upper layer and a fixed nutrient concentration in the lower. Evans and Parslow provided a more complete representation of the interaction of the marine ecosystem with its physical environment by allowing the depth of the mixed layer to vary seasonally with direct impacts on the model state variables. As the mixed layer deepens, nutrients are entrained from below while phytoplankton density is diluted because their surface layer biomass is spread over a greater depth. Conversely, as the mixed layer shallows, the concentrations of nutrients and phytoplankton are unchanged although losses occur on a per unit area $\left(\mathrm{m}^{-2}\right)$ basis. As many zooplankton can swim, Evans and Parslow assumed that they are able to avoid detrainment in a similar manner to the assumptions of prior models (e.g. Steele, 1958; Riley et al., 1949) in which case their concentration increases as MLD decreases.

Evans and Parslow (1985) also took seasonal and daily irradiance forcing into consideration, in combination with depth integration of a non-linear $P-I$ curve. As opposed to previous studies that had used observations, variation in light at the ocean surface was calculated from standard trigonometric/astronomical formulae (Brock, 1981), with transmission losses in the atmosphere as $70 \%$ of cloud cover and photosynthetically active radiation (PAR) as three-eighths of total irradiance. Variation in light with time of day was assumed to be triangular (Steele, 1962), permitting analytic integration in time. A notable contribution of Evans and Parslow's (1985) paper is the appendix which provides the equations required to construct a model subroutine to cal- culate daily depth-integrated photosynthesis in a model layer as a function of noon irradiance (PAR entering the layer from above), day length, phytoplankton concentration, rate of light extinction (Beer's law) and parameters for maximum photosynthesis and initial slope that define the $P-I$ curve.

In common with their predecessors, Evans and Parslow were interested in the factors controlling the initiation of the spring phytoplankton bloom, focussing on the role of vertical mixing. Bloom initiation, they concluded, required a low rate of primary production over winter, which is to be expected in the North Atlantic due to deep mixed layers at that time, and is also linked to coupling between phytoplankton and grazers. The simplicity of the slab model was key to their conclusions as articulated in their own words: "It is worth emphasising the advantages of analysing simple models, and simplifying models until they can be analysed". The controls on phytoplankton dynamics in high-nutrient lowchlorophyll (HNLC) areas such as the subarctic Pacific has remained a topical issue ever since, in large part because limitation by iron is also indicated (Martin et al., 1994; Coale et al., 1996), but the role of grazing and the link between phytoplankton-zooplankton coupling and mixed layer depth remains firmly established as a key mechanism in these systems (Frost, 1987; Fasham, 1995; Chai et al., 2000; Smith Jr. and Lancelot, 2004).

Perhaps the most famous slab modelling paper, published 5 years after Evans and Parslow (1985), is the study of nitrogen cycling in the Sargasso Sea by Fasham et al. (1990; henceforth FDM90). It is by far the most highly cited marine ecosystem model (Arhonditsis et al., 2006, noted that it had accumulated 405 ISI cites by November 2005; this number has increased to 758 as of May 2015). In terms of physical structure, Fasham's model used the same basic slab construct as in Evans and Parslow (1985), with seasonally varying mixed layer depth and irradiance forcing. The novel aspects of FDM90 were instead related to additional complexity of the ecosystem, expanding from a simple NPZ to explicitly separate new and regenerated production by including state variables for nitrate and ammonium (critical for calculating the $f$ ratio; Eppley and Peterson, 1979), as well as having a simple microbial loop of dissolved organic nitrogen and bacteria. Sinking detritus was also added as a state variable, facilitating the prediction of export flux. The success of this model was due to it being the first attempt to fully elucidate the processes involved in the recycling of nitrogen in the euphotic zone, as well as the complimentary roles of zooplankton and bacteria. The simplified physics of the model allowed it to be run on PCs of that era and Fasham purportedly distributed the code on floppy disks, allowing other researchers to run the model on their PCs.

The description of the marine ecosystem provided by FDM90 has largely served as the foundation for marine ecosystem modelling ever since. With the advent of increasing computer power, as well as increasing interest in the spatio-temporal behaviour of plankton systems, most mod- 
Table 1. Characteristics of published slab models.

\begin{tabular}{|c|c|c|c|c|c|}
\hline Reference & Location & Structure & MLD & Irradiance & Photosyn. \\
\hline Evans and Parslow (1985) & $\begin{array}{l}\text { Flemish Cap, } \\
\text { subarctic Pacific }\end{array}$ & NPZ & clim. & astronomical & E\&P85 \\
\hline Frost (1987) & subarctic Pacific & $\mathrm{NP}(Z)$ & clim. & data & numeric \\
\hline Fasham et al. (1990) & Sargasso Sea & 2NPZDB (DOM) & clim. & astronomical & E\&P85 \\
\hline Robinson et al. (1993) & Pacific upwelling & $\mathrm{P} 2 \mathrm{Z}$ & $f$ (winds) & astronomical & numeric? \\
\hline Fasham (1995) & $\begin{array}{l}\text { subarctic Pacific, } \\
\text { North Atlantic }\end{array}$ & 2NPZDB (DOM) & clim. & astronomical & E\&P85 \\
\hline Matear (1995) & subarctic Pacific & 2NP2ZDB (DOM) & clim. & data & E\&P85 \\
\hline Hurtt and Armstrong (1996) & Sargasso Sea & $2 \mathrm{NPR}$ & clim. & astronomical & E\&P85 \\
\hline Popova et al. (1997) & none (theoretical) & NPZD & hypothet. & astronomical & E\&P85 \\
\hline Anderson and Williams (1998) & English Channel & 2NPZDB (DOM) & clim. & astronomical & A93 \\
\hline Spitz et al. (1998) & Sargasso Sea & 2NPZDB (DOM) & clim. & astronomical & E\&P85 \\
\hline Fennel et al. (2001) & Sargasso Sea & NPZD & clim. & astronomical & E\&P85 \\
\hline Natvik et al. (2001) & Flemish Cap & NPZ & model & astronomical & E\&P85 \\
\hline Schartau et al. (2001) & Sargasso Sea & NPZ & 1989-1993 & astronomical & E\&P85 \\
\hline Spitz et al. (2001) & Sargasso Sea & 2NPZDB (DOM) & 1989-1993 & astronomical & E\&P85 \\
\hline Hemmings et al. (2004) & North Atlantic & NPZ & clim. & data & E\&P85 \\
\hline Onitsuka and Yanagi (2005) & Japan Sea & $\begin{array}{l}\text { NPZD, } \\
\text { 2N2P3Z (DOM) }\end{array}$ & clim. & data & numeric \\
\hline Findlay et al. (2006) & None (theoretical) & NP & hypothet. & none & B\&P05 \\
\hline Mitra et al. (2007) & North Atlantic & 2NPZDB (DOM) & clim. & astronomical & E\&P85 \\
\hline Mitra (2009) & North Atlantic & 2NPZDB (DOM) & clim. & astronomical & E\&P85 \\
\hline Llebot et al. (2010) & Mediterranean Bay & 2N2PD (DOM) & $f(\mathrm{R}$ no. $)$ & astronomical & numeric \\
\hline Kidston et al. (2013) & Southern Ocean & NPZD & model & model & E\&P85 \\
\hline
\end{tabular}

MLD: clim. (climatological from data); hypothet. (hypothetical); $f$ (R no.) (function of Richardson number). Photosynthesis calculation (photosyn.): E\&P85 (Evans and Parslow, 1985); A93 (Anderson, 1993); B\&P05 (Boushaba and Pascual, 2005).

elling studies are now undertaken in 1-D or 3-D physical frameworks. Nevertheless, many slab modelling studies have been published since FDM90 which follow the basic design described above, or slight modifications thereof (Table 1). A range of ecosystem models of varying complexity have been incorporated within slab physics and applied to contrasting sites throughout the world ocean. The basic physical construction is similar in most cases consisting of a classic slab structure with a seasonal cycle of mixed layer depth specified from data and seasonal irradiance from standard trigonometric equations. Remarkably, Evans and Parslow's (1985) equations for calculating daily depth-integrated photosynthesis have prevailed and been used in most studies. A more sophisticated calculation method was developed by Morel (1988, 1991) and a simplified form of this (Anderson, 1993) is examined in Sect. 4.3. The models in Table 1 have been used for a diverse range of applications including studies of parameter optimisation (Spitz et al., 1998; Fennel et al., 2001; Schartau et al., 2001; Hemmings et al., 2004), parameter sensitivity analysis (Mitra, 2009; Mitra et al., 2007, 2014), phytoplankton bloom dynamics (Findlay et al., 2006), nutrient cycling via organic and inorganic pathways (Llebot et al., 2010), primary production in HNLC systems (Kidston et al., 2013) and primary production and export flux in contrasting regions (Fasham, 1995; Onitsuka and Yanagi, 2005).

\section{Model description}

We demonstrate the use of EMPOWER-1.0 using a simple NPZD ecosystem model and forcing for four time series stations in the ocean. The code is readily adapted to incorporate other ecosystem models, including the relatively complex models of the modern era, and/or forcing for other ocean sites.

\subsection{Slab setup and forcing}

The model uses slab physics as per Evans and Parslow (1985), namely a seasonally varying surface mixed layer that contains the ecosystem positioned above a deep homogeneous layer containing unchanging nutrient and no plankton (Fig. 2). We have also included temperature dependencies for the physiological rates in the ecosystem model (see below). Our model was set up for four stations, two in the North Atlantic (stations BIOTRANS, $47^{\circ} \mathrm{N}$, $20^{\circ} \mathrm{W}$ and India, $60^{\circ} \mathrm{N}, 20^{\circ} \mathrm{W}$ ) and two HNLC systems (stations Papa in the North Pacific, $50^{\circ} \mathrm{N}, 145^{\circ} \mathrm{W}$ and KERFIX in the Southern Ocean, $50^{\circ} 40^{\prime} \mathrm{S} 68^{\circ} 25^{\prime} \mathrm{E}$ ). These stations were chosen because of their contrasting environments, as illustrated by the differences in forcing variables: seasonally varying MLD, irradiance $(I)$ and sea surface temperature $(T)$ (Fig. 3), as well as deep nitrate $\left(N_{0}\right.$; see below). Mixed layer depths were taken from the World 


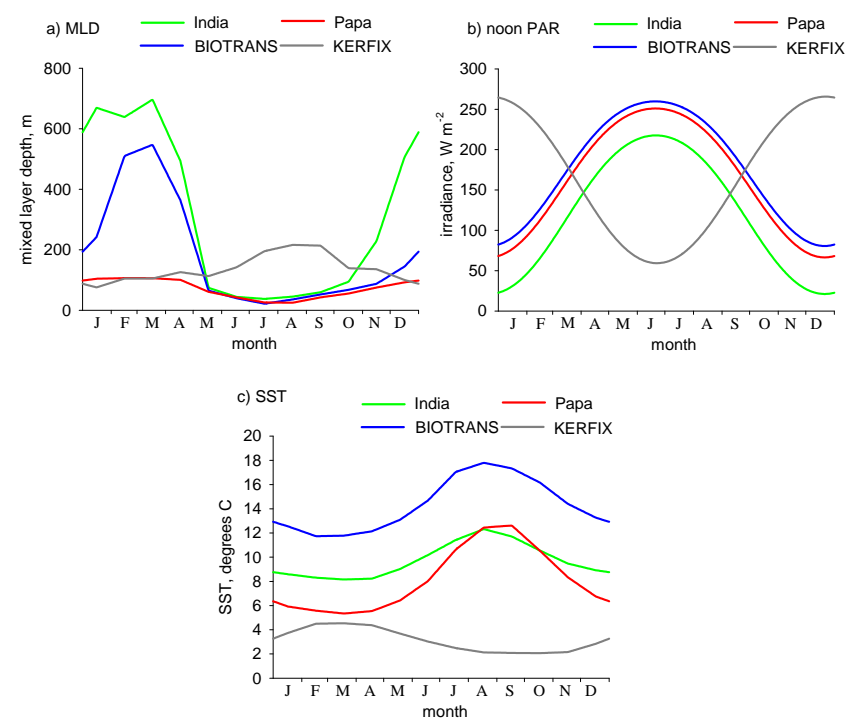

Figure 3. Model forcing for stations India $\left(60^{\circ} \mathrm{N}, 20^{\circ} \mathrm{W}\right)$, BIOTRANS $\left(47^{\circ} \mathrm{N}, 20^{\circ} \mathrm{W}\right)$, Papa $\left(50^{\circ} \mathrm{N}, 145^{\circ} \mathrm{W}\right)$ and KERFIX $\left(50^{\circ} 40^{\prime} \mathrm{S}, 68^{\circ} 25^{\prime} \mathrm{E}\right)$ : (a) mixed layer depth $(\mathrm{m})$, (b) noon irradiance $\left(\mathrm{W} \mathrm{m}^{-2}\right)$, (c) sea surface temperature $\left({ }^{\circ} \mathrm{C}\right)$.

Ocean Atlas 2009 (WOA; Antonov et al., 2010; Locarnini et al., 2010). In common with most previous slab modelling studies, noon (peak daily) irradiance at the ocean surface is calculated, for a given latitude as a function of time of year, using standard trigonometric/astronomical equations. The effect of clouds on atmospheric transmission was calculated using the model of Reed (1977). The equations for irradiance forcing are not usually provided as part of published model descriptions but, for completeness, they are listed here in Appendix A.

The bottom layer in most slab models is assumed to have a fixed concentration of nutrient, $N_{0}$. There is in reality a gradient of nutrient with depth and this can be represented empirically in slab models using simple functions of nutrients versus depth (Frost, 1987; Steele and Henderson, 1993; Fasham, 1995). We adopted this approach here for stations BIOTRANS and India, using simple linear relationships with depth $(z)$ :

$N_{0}(z)=a_{N} z+b_{N}$.

The regression coefficients were fitted from WOA data (Garcia et al., 2010) for subthermocline $\mathrm{NO}_{3}(z>100 \mathrm{~m})$. Resulting values for $a_{N}$ and $b_{N}$ were 0.0174 and 3.91 for station BIOTRANS and 0.0074 and 10.85 for station India. There were no obvious relationships between $N_{0}$ and depth for the two HNLC stations and so mean (fixed) values of 26.1 and $14.6 \mathrm{mmol} \mathrm{N} \mathrm{m}^{-3}$ were used for $N_{0}$ for KERFIX and Papa respectively.

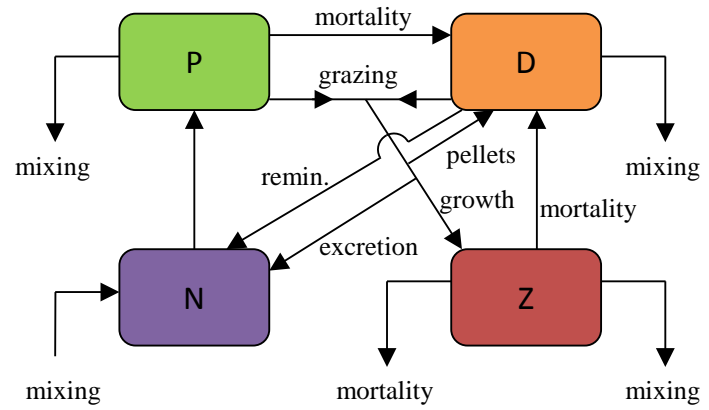

Figure 4. Structure of the NPZD model.

\subsection{Ecosystem model description}

The NPZD ecosystem model we have implemented in EMPOWER is presented in Fig. 4 with dissolved inorganic nitrogen $(N$; the sum of nitrate and ammonium), phytoplankton $(P)$, zooplankton $(Z)$ and detritus $(D)$ as state variables. It is a simplification of the marine ecosystem inspired by that of FDM90 with improved formulations for multiple-prey grazing, plankton mortality, nutrient regeneration and other detrital loss terms, as well as alterations to the parameterisation. The equations are described below; model parameterisation is described in Sect. 4.1. The phytoplankton equation is

$$
\frac{\mathrm{d} P}{\mathrm{~d} t}=\mu_{P} P-G_{P}-m_{P} P-m_{P 2} P^{2}-\frac{\left(w_{\mathrm{mix}}+H^{\prime}(t)\right) P}{H(t)},
$$

where the terms are growth, grazing and non-grazing mortality (linear and quadratic), physical losses due to mixing across the bottom of the mixed layer, and dilution effects of entrainment. $H(t)$ is mixed layer depth (m) at time $t$ and $H^{\prime}(t)$ denotes the rate of change of $H$ when $\mathrm{d} H / \mathrm{d} t$ is positive (dilution). As explained above, when $\mathrm{d} H / \mathrm{d} t$ is negative the change in phytoplankton density due to detrainment of mass from the mixed layer is exactly balanced by the increasing phytoplankton density due to decreases in volume and therefore detrainment does not alter the concentration of remaining biomass. Variable $\mu_{P}$ is the vertically averaged temperature-dependent daily growth rate, defined as the product of a temperature-dependent maximum growth rate, $\mu_{P}^{\max }(T)$, and non-dimensional limitation terms for nutrients and light, $L_{N}(N)$ and $L_{I}(I(t, z))$ :

$\mu_{P}=\mu_{P}^{\max }(T) L_{N}(N) L_{I}(I(t, z))$.

Note that $\mu_{P}$ is calculated on a daily basis averaging over the time of day $(t)$ and depth $(z)$. Temperature and nutrients are assumed to be uniformly distributed throughout the mixed layer, in which case $\mu_{P}$ is

$\mu_{P}=\frac{\mu_{P}^{\max }(T) L_{N}(N)}{24 H} \int_{0}^{24} \int_{0}^{\mathrm{h}} L_{I}(I(t, z)) \mathrm{d} z \mathrm{~d} t$. 


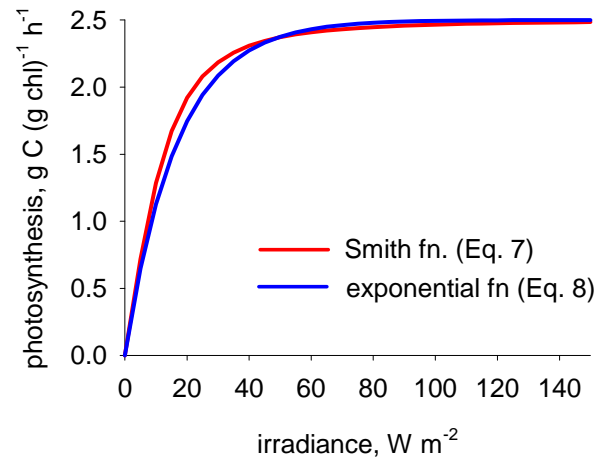

Figure 5. Photosynthesis-irradiance curves with parameter settings $V_{P}^{\max }=2.5 \mathrm{~g} \mathrm{C}(\mathrm{g} \mathrm{chl})^{-1} \mathrm{~h}^{-1}$ and $\alpha=0.15 \mathrm{gC}(\mathrm{g} \mathrm{chl})^{-1} \mathrm{~h}^{-1}$ $\left(\mathrm{W} \mathrm{m}^{-2}\right)^{-1}$; Smith function (Eq. 7) and exponential function (Eq. 8).

With the assumption of balanced growth, $\mu_{P}^{\max }(T)$ is equal to the equivalent maximum photosynthetic rate, $V_{P}^{\max }(T)$. The temperature dependence of photosynthesis is from Eppley (1972):

$V_{P}^{\max }(T)=V_{P}^{\max }(0) 1.066^{T}$,

where $V_{P}^{\max }(0)$ is photosynthesis at $0^{\circ} \mathrm{C}$. Note that this exponential relationship is equivalent to a $Q_{10}$ of 1.895 .

The usual way NPZD-type models characterise nutrient limitation of phytoplankton growth rate by nutrients, $L_{N}(N)$, is calculated as a Michaelis-Menten (or Monod) relationship:

$L_{N}(N)=\frac{N}{k_{N}+N}$,

where $k_{N}$ is the half-saturation constant.

The calculation of $L_{I}$ is the most mathematically complicated aspect of characterising phytoplankton growth in this model as it takes into consideration both seasonal and diurnal patterns of irradiance arriving at the ocean surface $\left(I_{0}\right)$, attenuation of irradiance with depth and photosynthesis as a function of light intensity. Light is assumed to vary with depth according to Beer's law $\left(I=I_{0} \exp \left(-k_{\mathrm{PAR}} z\right)\right)$, where $k_{\text {PAR }}$ is the attenuation coefficient, and photosynthesis calculated using a $P-I$ curve. The daily depth-average photosynthetic rate is calculated over the course of the day using an assumed daily variation of light, from which the daily average is derived. The user of EMPOWER is provided with a choice between two $P-I$ curves, a Smith function (Eq. 7) and an exponential function (Eq. 8) (Fig. 5):

$$
\begin{aligned}
V_{P} & =\frac{\alpha I V_{P}^{\max }}{\sqrt{\left(V_{P}^{\max }\right)^{2}+\alpha^{2} I^{2}}}, \\
V_{P} & =V_{P}^{\max }\left(1-\exp \left(-\alpha I / V_{P}^{\max }\right)\right) .
\end{aligned}
$$

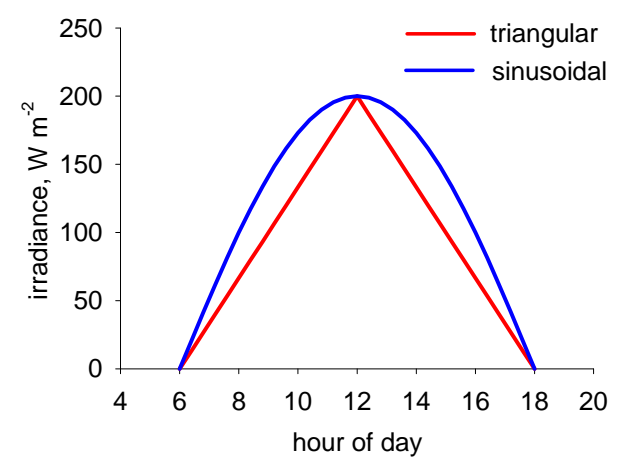

Figure 6. Triangular versus sinusoidal patterns of diel irradiance illustrated for a $12 \mathrm{~h}$ day and noon irradiance of $200 \mathrm{~W} \mathrm{~m}^{-2}$.

Integration with depth (inner integral of Eq. 4) can be calculated analytically for either of the two $P-I$ curves; equations are provided in Appendix B. The default method of handling the diurnal variation in irradiance at the ocean surface (outer integral of Eq. 4) is to do a numeric integration. The user may choose between assuming either a sinusoidal (Platt et al., 1990) or triangular (Steele, 1962; Evans and Parlsow, 1985) pattern of irradiance throughout each day, from sunrise to sunset and peaking at noon (Fig. 6).

Analytic depth integrals require a Beer's law attenuation of light within the water column characterised by a single attenuation coefficient, $k_{\mathrm{PAR}}$. The simplest assumption, provided as the first of two options in EMPOWER, is that $k_{\text {PAR }}$ is the sum of attenuation due to water and phytoplankton, parameters $k_{w}$ and $k_{c}$, respectively:

$k_{\mathrm{PAR}}=k_{w}+k_{c} P$.

Parameters $k_{w}$ and $k_{c}$ are often assigned values of 0.04 and $0.03 \mathrm{~m}^{2}(\mathrm{mmol} \mathrm{N})^{-1}$ respectively (e.g. FDM90); these values are used here.

The assumption of a single mixed layer value of $k_{\mathrm{PAR}}$ is questionable because in reality the value of $k_{\mathrm{PAR}}$ varies with depth as a result of the changing spectral properties of the irradiance field. Red light is mostly absorbed by water in the upper few metres while blue penetrates deepest, with relatively efficient absorption by chlorophyll at both wavelengths. Based on a complex treatment of submarine light (Morel, 1988), a piecewise approach to light attenuation was developed by Anderson (1993) with different values, $k_{\mathrm{PAR}, i}$, with $i=1$ for depth range $0-5 \mathrm{~m}, i=2$ for depth range 5$23 \mathrm{~m}$ and $i=3$ for depths $>23 \mathrm{~m}$, in each case $k_{\mathrm{PAR}}(i)$ is related to pigment (chlorophyll) concentration, $C$ :

$$
\begin{aligned}
k_{\mathrm{PAR}, i}= & b_{0, i}+b_{1, i} C^{1 / 2}+b_{2, i} C+b_{3, i} C^{3 / 2} \\
& +b_{4, i} C^{2}+b_{5, i} C^{5 / 2} .
\end{aligned}
$$

This approach to light attenuation is provided as the default option for use in EMPOWER. The values of the polynomial coefficients $\left(b_{0, i}-b_{5, i}\right)$ are listed in Table 2 . 
Table 2. Coefficients for use in the Anderson (1993) calculation of light attenuation (Eq. 10).

\begin{tabular}{lll}
\hline First layer $(0-5 \mathrm{~m})$ & Second layer $(5-23 \mathrm{~m})$ & Third layer $(>23 \mathrm{~m})$ \\
\hline$b_{0,1}=0.13096$ & $b_{0,2}=0.041025$ & $b_{0,3}=0.021517$ \\
$b_{1,1}=0.030969$ & $b_{1,2}=0.036211$ & $b_{1,3}=0.050150$ \\
$b_{2,1}=0.042644$ & $b_{2,2}=0.062297$ & $b_{2,3}=0.058900$ \\
$b_{3,1}=-0.013738$ & $b_{3,2}=-0.030098$ & $b_{3,3}=-0.040539$ \\
$b_{4,1}=0.0024617$ & $b_{4,2}=0.0062597$ & $b_{4,3}=0.0087586$ \\
$b_{5,1}=-0.00018059$ & $b_{5,2}=-0.00051944$ & $b_{5,3}=-0.00049476$ \\
\hline
\end{tabular}

The diurnal variation in light at the ocean surface over the course of a day may be reasonably approximated by a sinusoidal function that is symmetric about noon irradiance (Platt et al., 1990). Further simplification is possible by use of a linear model, i.e. use of a triangular model centred at noon (e.g. Steele, 1962; Evans and Parlsow, 1985) because this simplifies the time integration. It should be noted here that despite Evans and Parslow's (1985) claim that differences between the triangular and sinusoidal approximations are minimal if the area under the curve is the same, they did not make the "equivalent area" adjustment to their formula, nor is their statement generically true (i.e. it depends on the peak light intensity, the attenuation of light with depth and the non-linear $P-I$ relationship).

In EMPOWER, the default method of handling the diurnal variation in irradiance at the ocean surface is to do a numeric integration. Undertaking a numerical time integral involves computational cost and two empirical methods (Evans and Parslow, 1985; Anderson, 1993) have been published that provide analytic calculations (i.e. pre-determined formulae) for daily depth-integrated photosynthesis in a water column. Both are provided as options for use in EMPOWER and have the advantage of faster run time. The first of the two EMPOWER options is the depth-averaged light-dependent calculation of growth of Evans and Parslow (1985) which assumes a triangular pattern of daily irradiance, Beer's law for light attenuation (Eq. 9) and a Smith function as the $P$ $I$ curve (Eq. 7). It has been a popular choice in previous slab modelling studies (Table 1). The second option is from Anderson (1993), which was developed as an empirical approximation to the spectrally resolved model of light attenuation and photosynthesis of Morel (1988) used in combination with the polynomial method of integrating daily photosynthesis of Platt et al. (1990). It assumes a sinusoidal pattern of irradiance through the day, a piecewise Beer's law light attenuation (Eq. 10) and an exponential function as the $P$ $I$ curve (Eq. 8). Parameter $\alpha$, the initial slope of the $P-I$ curve, is also spectrally dependent. The method of Anderson (1993) calculates the variation of $\alpha$ with depth as a function of chlorophyll in the water column. Daily photosynthesis is then calculated using a polynomial approximation. The methods for calculating daily depth-integrated photosynthesis of Evans and Parslow (1985) and Anderson (1993) are non-trivial and, for completeness, the equations are supplied in Appendix C.

Grazing by zooplankton is assumed to be on both phytoplankton and detritus. This choice was made in part to illustrate how to implement ingestion on multiple prey types, as such functions are used for more complex models (e.g. when there are multiple phytoplankton size classes or functional types and/or omnivory by zooplankton). Many multiplegrazing formulations, however, comprise questionable assumptions about zooplankton feeding behaviour (Gentleman et al., 2003). For example, the multiple-prey grazing formula used in FDM90 is classified as an active switching response (Gentleman et al., 2003) which can display anomalous behaviour such as suboptimal feeding (i.e. ingestion rates decreasing when prey availability increases). We have therefore opted to improve upon Fasham's choice by using a different multiple-prey response, but one that is nevertheless commonplace in the literature. Specifically, we have adopted a passive switching response where density dependence of the prey preferences arises due to inherent differences in the singleprey responses (see Gentleman et al., 2003). This Sigmoidal (or Holling Type 3) response is characterised as (Fig. 7)

$$
\begin{gathered}
G_{P}=\left(\frac{I_{\max } \hat{\varphi}_{P} P}{k_{Z}^{2}+\hat{\varphi}_{P} P+\hat{\varphi}_{D} D}\right) Z, \\
\hat{\varphi}_{P}=\varphi_{P} P, \hat{\varphi}_{D}=\varphi_{D} D, \\
G_{D}=\left(\frac{I_{\max } \hat{\varphi}_{D} D}{k_{Z}^{2}+\hat{\varphi}_{P} P+\hat{\varphi}_{D} D}\right) Z,
\end{gathered}
$$

where the terms in parentheses are the zooplankton specific ingestion rates $I_{P}$ and $I_{D}$ respectively. This formulation implies that the single-prey responses for both phytoplankton and detritus are each sigmoidal (Type 3). Parameter $I_{\max }$ is the maximum specific grazing rate, which is the same for both phytoplankton and detritus and equates to their single-prey maximum ingestion rates. Although parameters $\varphi_{P}$ and $\varphi_{D}$ are often called preferences in the literature, the actual prey preferences associated with this response (i.e. relative amount in the diet as compared to the environment) are density-dependent, with the relative preference for phytoplankton to detritus determined by $\operatorname{pref}_{P: D}=\frac{\varphi_{P} P}{\varphi_{D} D}=\frac{\hat{\varphi}_{P}}{\hat{\varphi}_{D}}$. The $\varphi$ parameters actually relate to the half-saturation constants associated with the single-prey functional responses. Specifically, $\varphi_{P}=\frac{k_{Z}^{2}}{k_{P}^{2}}$, where $k_{P}$ is the half-saturation value for the Type 3 single-prey response for ingestion of phytoplankton, and $\varphi_{D}$ is defined similarly. Parameter $k_{Z}$, which is often referred to as the half-saturation value in the literature, is actually an arbitrary parameter (i.e. this formulation is over-parameterised; see Gentleman et al., 2003) whose value determines the assumed single-prey half-saturation constants based on choices for the $\varphi$ parameters.

The Sigmoidal response assumes an interference effect of alternative prey in that as detritus increases, ingestion of phy- 

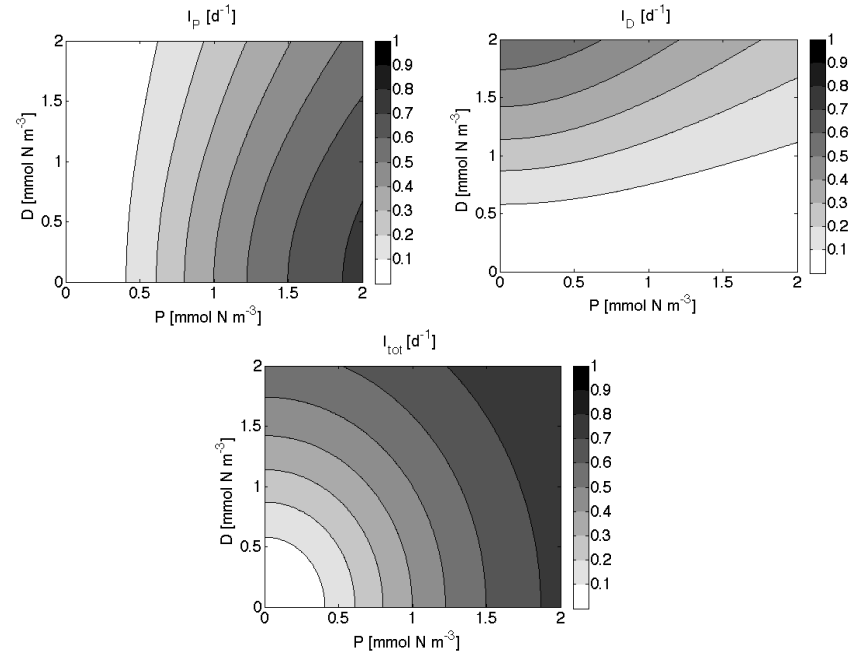

Figure 7. Contours of the zooplankton specific ingestion rates $\left(I_{P}\right.$, $I_{D}$ ) versus densities of the two prey types ( $P$ : phytoplankton, $D$ : detritus) as characterised by the sigmoidal grazing response (Eqs. 11, 12) using parameters $I_{\max }=1 \mathrm{~d}^{-1}, k_{Z}=0.52 \mathrm{mmol} \mathrm{N} \mathrm{m}^{-3}$, $\varphi_{P}=0.67$ and $\varphi_{D}=0.33$. Upper panels illustrate assumed interference effect of one prey type over another, e.g. for a given $P$, increasing $D$ reduces $I_{P}$. The lower panel illustrates assumed optimal feeding (i.e. total ingestion, $\mathrm{I}_{\text {tot }}$, always increases with increase in $P$ or $D$ ) and the benefit of generalism (i.e. increase in $\mathrm{I}_{\text {tot }}$ due to consumption of $P$ and $D$ vs. just $P$ ).

toplankton decreases (with the same interaction for phytoplankton and ingestion of detritus). This interference effect is not so great as losing the benefit of generalism, i.e. total ingestion always increases for an increase in total prey density. The non-equal preferences reduce the interference effect for phytoplankton, i.e. the contours in the first panel of Fig. 7 are more vertical than for equal preferences. The corollary effect is that the increased ingestion by consuming both phytoplankton and detritus versus just phytoplankton is reduced as compared to when prey have equal preferences.

Regarding phytoplankton non-grazing mortality, FDM90 has the usual choice of a linear term although non-linear approaches are also possible, e.g. the use of a MichaelisMenten saturating function by Fasham (1993). We opted for the more flexible approach of using both linear and nonlinear terms (Yool et al., 2011, 2013a). The former may account for metabolic losses or natural mortality. The use of an additional non-linear term represents density-dependent loss processes, notably mortality due to infection by viruses. The abundance of viruses is highly dependent on the density of potential host cells (e.g. Weinbauer, 2004) and, as reviewed by Danovaro et al. (2011), there is "compelling" evidence that, at least in some instances, viruses are responsible for the demise of phytoplankton blooms based on observations of high proportions (10-50\%) of infected cells (e.g. Bratbak et al., 1993, 1996). A quadratic form was used for the nonlinear mortality term (e.g. Kawamiya et al., 1995; Oschlies and Schartau, 2005) and all phytoplankton non-grazing mortality losses were allocated to detritus.

The equation for rate of change of zooplankton density is

$$
\begin{aligned}
\frac{\mathrm{d} Z}{\mathrm{~d} t}= & \left(\beta k_{N}\left(G_{P}+G_{D}\right)\right)-\left(m_{Z} Z+m_{Z 2} Z^{2}\right) \\
& -\frac{\left(w_{\operatorname{mix}}+H^{\prime}(t)\right) Z}{H(t)},
\end{aligned}
$$

where the terms are growth, mortality (linear and quadratic) and losses due to mixing and changing MLD. Zooplankton growth can be described as the product of gross growth efficiency (GGE) and intake, where GGEs are typically between 0.2 and 0.3 (Straile, 1997). Gross growth efficiency is itself the product of absorption efficiency, $\beta$ (more commonly, but incorrectly, known as assimilation efficiency; e.g. see Mayor et al., 2011) and net production efficiency, $k_{\mathrm{NZ}}$. Splitting into these separate parameters (Table 3) permits three-way fractionation of intake between egestion (i.e. faecal pellet production, $1-\beta)$, growth $\left(\beta \cdot k_{\mathrm{NZ}}=\mathrm{GGE}\right.$; first term in Eq. 13) and excretion $\left(\beta\left(1-k_{\mathrm{NZ}}\right)\right)$.

A variety of formulations exist in ecosystem models to describe zooplankton mortality and the appropriate functional form has been and continues to be a hotly debated topic (Steele and Henderson, 1992; Edwards and Yool, 2000; Mitra et al., 2014). Most common are the linear and quadratic terms, although some authors have chosen to employ other non-linear functions (e.g. Fasham, 1993 used a MichaelisMenten relationship). As with phytoplankton, we used both linear and quadratic non-linear terms (Yool et al., 2011). The linear term represents density-independent natural mortality, whereas the quadratic term is considered to be due to predation by carnivores (whose population tracks that of the zooplankton). The different sources of mortality result in different fates for these terms. Loss from natural mortality is allocated to modelled detritus, which implies a broader size class of modelled particulates (and therefore higher sinking rates) than when just phytoplankton death contributes to this variable.

The fate of the predation-related mortality is less obvious because the metabolic activity of higher predators results in ingested material being converted into dissolved nutrients as well as larger particulates (e.g. fecal pellets and death). Moreover, the higher predators may export material from the local region with migration. FDM90, along with a suite of follow-on models, therefore chose to allocate predation-related zooplankton mortality between nutrients (ammonium and DON, attributed to excretion by higher predators) and material that is immediately exported from the system (e.g. attributed to fast-sinking detritus generated by higher predators). Similarly, Steele and Henderson (1992) also allocated zooplankton mortality to export. Nevertheless, many past and recently published marine ecosystem modelling studies allocate all of zooplankton mortality to detritus (Oschlies and Schartau, 2005; Salihoglu et al., 2008; Hinckley et al., 2009; Ye et al., 2012). We argue, however, 
that this is not necessarily realistic given that detrital particles related to higher predators are larger and therefore even faster-sinking than that produced by the modelled plankton. We have therefore here adopted to follow the sage approach of the model pioneers and assume that the predation-related mortality represented by our quadratic term is instantly exported and thereby entirely lost from the surface mixed layer of the model. As with phytoplankton, zooplankton are subject to changes in concentration via mixing and changes in MLD.

The equation for the rate of change of dissolved inorganic nitrogen (DIN) density is

$$
\begin{aligned}
\frac{\mathrm{d} N}{\mathrm{~d} t}= & -\mu_{P} P+\beta\left(1-k_{\mathrm{NZ}}\right)\left(G_{P}+G_{D}\right) \\
& +m_{D} D+\frac{\left(w_{\text {mix }}+H^{\prime}(t)\right)\left(N_{0}-N\right)}{H} .
\end{aligned}
$$

DIN is taken up by phytoplankton (first term) and, via the food web, regenerated with the second and third terms in Eq. (14) representing excretion by zooplankton and remineralisation of detritus respectively. The fourth term represents the net transport due to mixing (i.e. supply by the deep water and loss from the surface layer). The last term represents the net effect of volume changes, i.e. increases in DIN density due to supply of deep water nutrients through entrainment and decreases in DIN density due to volume increases associated with entrainment.

Finally, the detritus equation is

$$
\begin{aligned}
\frac{\mathrm{d} D}{\mathrm{~d} t}= & m_{P} P+m_{P 2} P^{2}+m_{Z} Z+(1-\beta)\left(G_{P}+G_{D}\right)-G_{D} \\
& -m_{D} D-\frac{\left(w_{\operatorname{mix}}+H^{\prime}(t)+v_{D}\right) D}{H} .
\end{aligned}
$$

Detritus is produced by phytoplankton mortality, zooplankton natural mortality (linear term) and as zooplankton egestion (faecal pellet production). It is lost by zooplankton grazing and is also remineralised at a constant rate, $m_{D}$. Detritus is mixed and subject to changes via the seasonal cycle of MLD in the same manner as phytoplankton and zooplankton (terms six and seven), and also experiences losses due to gravitational sinking (last term). This occurs at rate $v_{D}\left(\mathrm{~m} \mathrm{~d}^{-1}\right)$ and provides direct export of particulate organic matter to the layer below (where it is implicitly remineralised back to DIN).

The first results Sections $(4.1,4.2)$ are devoted to parameterising the model, in the first instance, for station BIOTRANS and a detailed description of values assigned to model parameters is provided therein.

\subsection{Setup in $\mathbf{R}$}

We have chosen to code our model in the $\mathrm{R}$ programming language which can be readily downloaded for free over the Internet. Input and output files are in ASCII text (.txt) format, avoiding the use of proprietary software. The structure of the code is designed to be transparent, where possible using conventional syntax common to different programming languages such as the use of loops and block IF statements. Where possible, we have followed what we consider to be best practice in developing the code, which includes the following.

i. Creation of a fixed segment of core code that handles the numerical integration, as well as writing to output files. Being fixed, this segment does not require alteration in the event of changes to the ecosystem model formulation, nor indeed if an entirely new ecosystem model is implemented.

ii. The ecosystem model formulation, i.e. the specification of the terms in the differential equations and calculation of their rates of change, is handled by a function (FNget_flux) that is external to the core code.

iii. The specification of parameter values and run characteristics (e.g. time step, run duration, as well as flags for choices between different formats for export to output files, choice of ocean location and for different parameterisations of key processes) is via text files that are read in at the onset of each simulation. Thus, there is no need to enter or alter the model code when changing parameter values or other model settings.

iv. When a model run finishes, the summed annual fluxes associated with each term in the differential equations is displayed on the computer screen along with a report as to whether mass balance is achieved for each state variable (over the last year of simulation). Basic checking of mass balance is useful for ensuring that the model equations are error-free.

v. Regimented layout for clarity with extensive commenting throughout.

The $\mathrm{R}$ programming language is supported by various libraries that can be accessed via the Internet. One such library is for solving ordinary differential equations (Soetaert et al., 2010). Using this library has the advantage of minimising the length of the code and offers flexibility in terms of a range of numerical methods. On the other hand, its implementation requires that various conventions are adhered to and these can be restrictive when it comes to producing ancillary code, e.g. the formatting and export of output files. As such, we opted to code the numerical solution of the ordinary differential equations (ODEs) manually within the core code of the model for the following reasons.

i. It offers full transparency for the interested user who wishes to see the method of integration.

ii. The use of manual code makes it considerably easier to export chosen variables and fluxes to output files in desired formats and frequencies. 


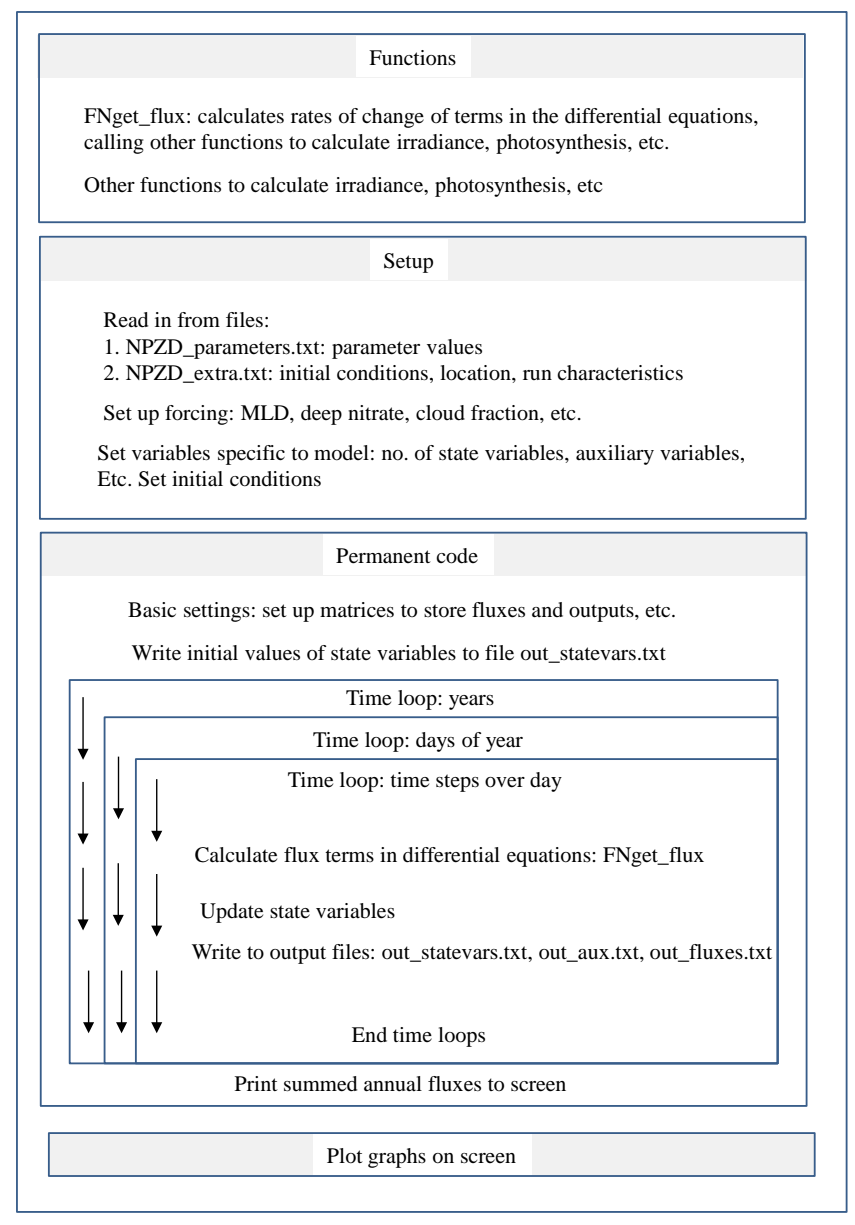

Figure 8. Structure of the model code.

iii. In our case, the user is given the choice between two integration methods, Euler and fourth order Runge Kutta (RK4). These methods, particularly the latter, are entirely sufficient for the numerical task at hand and the coding of them is straightforward.

iv. By using elementary syntax, the code can be easily altered or converted to other programming languages.

v. The code is stand alone and not subject to reformulation in the event of future changes in subroutine libraries.

The structure of the code is shown in Fig. 8. The functions come first, appearing prior to the core code in R. The key function call is FNget_flux which contains the ecosystem model specification (Sect. 3.2). The rate of change is calculated for each term in the differential equations and allocated to a 2-D array (flux no., state variable no.) which is then passed back to the core (permanent) code for processing. Other functions are FNdaylcalc (calculates length of day; Eq. A7), FNnoonparcalc (noon irradiance, PAR; Eq. A5), FNLIcalcNum (undertakes numerical (over time) calculation of daily depth-integrated photosynthesis), FNLI-
calcEP85 (calculates $L_{I}$ using the equations of Evans and Parslow, 1985; Appendix C1), FNaphy (calculates chlorophyll absorption, effectively parameter $\alpha$, in the water column after Anderson, 1993; Eq. C14) and FNLIcalcA93 (calculates $L_{I}$ using the equations of Anderson, 1993; Appendix C2).

Model setup comes next. Parameter values are read in from file NPZD_parms.txt. Simulation characteristics are then read in from file NPZDextra.txt. These include

i. initial values for state variables $(N, P, Z, D)$;

ii. run duration (years) and time step;

iii. choice of station: BIOTRANS, India, Papa, KERFIX;

iv. choice of photosynthesis calculation: numeric (default), Evans and Parslow (1985) or Anderson (1993);

v. choice of integration method: Euler or RK4;

vi. choice of output characteristics: none, last year only or whole simulation, and a frequency of once per day or every time step.

Model forcing for the chosen station of interest is then assigned. Monthly values of MLD and sea surface temperature are read in and subject to linear interpolation in order to derive daily forcing. Other forcing variables are also set: latitude, deep nitrate $\left(N_{0}\right.$; Eq. 1$)$ and cloud fraction. At the end of the setup section there are a few lines of code that need to be altered if the ecosystem model is changed. These lines tell the computer how many state variables the model has, the maximum number of flux terms associated with any one state variable and the maximum number of auxiliary variables to be stored for writing to output files.

An advantage of this structure is that an initial section of customisable code is followed by a section of permanent code that does not require adjustment in the event of changes to the equations that describe the ecosystem model, or indeed if a completely new ecosystem model is to be used. This code sets up a series of matrices to store fluxes and outputs and then integrates the model equations over time. State variables are updated and results exported to three output files: out_statevars.txt (state variables), out_aux.txt (chosen auxiliary variables) and out_fluxes.txt (all the terms in the differential equations). These text files are readily imported to, for example, Microsoft Excel.

Results are plotted graphically on the computer screen at the completion of each simulation run. The graph plotting code is necessarily model specific and needs to be updated by the user as required. $\mathrm{R}$ is a user friendly programming language in this regard and the code provided should be sufficient for the user to incorporate extra variables with ease.

Finally, a user guide is provided in Appendix D, outlining how to set up R, run the code, a summary of input and output files, and guidance on considerations when altering the ecosystem code and/or forcing. 


\section{Results}

Model results are presented in four sections. First, a simulation is shown for station BIOTRANS using parameters taken from the literature (Sect. 4.1). This station is chosen as our primary focus, inspired by the North Atlantic Bloom Experiment in 1989 as part of JGOFS (the Joint Global Ocean Flux Study; e.g. Ducklow and Harris, 1993; Lochte et al., 1993). It exhibits the characteristic spring blooming of phytoplankton of temperate latitudes, followed by relatively oligotrophic conditions over summer, and has been the subject of previous work using slab models (Fasham and Evans, 1995). Parameter tuning is then undertaken to fit all four ocean time series stations, BIOTRANS, India, Papa and KERFIX, to data for chlorophyll and nitrate at each site (Sect. 4.2). Moving on from the calibration of parameters, structural sensitivity analysis is then carried out by examining model sensitivity to equations for the calculation of daily depth-integrated photosynthesis (Sect. 4.3) and mortality terms for phytoplankton and zooplankton (Sect. 4.4).

The model is compared to seasonal data for chlorophyll and nitrate within the mixed layer, for each station. Nitrate data are climatological, from World Ocean Atlas 2009 (Garcia et al., 2010), as is the model forcing in terms of mixed layer depths and irradiance. Regarding chlorophyll, data are SeaWiFS (Sea-Viewing Wide Field-of-View Sensor) 8-day averages (O'Reilly et al., 1998), for which we had access to years 1998-2013. Averaging data across years to provide a climatological seasonal cycle of chlorophyll is not meaningful as key features, such as the spring phytoplankton bloom, are smoothed out because the bloom timing is variable between years. A characteristic year was therefore chosen for each station by firstly converting the data to $\log$ (chlorophyll), then calculating mean $\log$ (chlorophyll) for each year and finally selecting the median year (an odd number of years is required, so we used 1998-2012. The resulting year selections were 2002, 1998, 2007 and 2006 for stations BIOTRANS, India, Papa and KERFIX respectively. The entire data sets are shown with the multiple years overlaid in Fig. 9, with data for the selected median year highlighted.

It is not our objective here to provide thorough quantitative assessment of different model simulations in terms of objective quantification of model-data misfit but, rather, to demonstrate the utility of EMPOWER as a testbed for model evaluation. Different ecosystem models and associated data sets will necessarily require different skill metrics and so a lengthy description and use of quantitative metrics is not appropriate here. Very often anyway, as is the case here, visual inspection of model-data misfit is sufficient to determine the best options for model formulation/parameterisation. If quantitative methods are required, these are readily accessed from the literature (e.g. Lewis and Allen; 2009; Lewis et al., 2006).
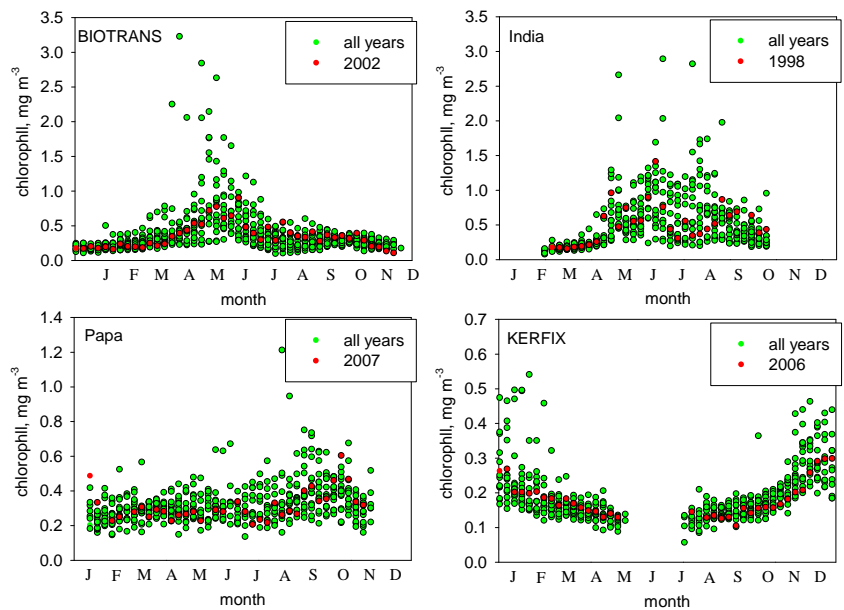

Figure 9. SeaWiFS chlorophyll data $\left(\mathrm{mg} \mathrm{m}^{-3}\right)$ for each of the four stations, years 1998-2013 overlaid, with selected median year (see text) highlighted.

\subsection{Parameter initialisation: station BIOTRANS}

Adjustment of parameters is a perennial problem for modellers. Parameters can be set from the literature, sometimes directly on the basis of observation and experiment, but the usual starting point is to take values from previously published modelling studies. Almost inevitably, however, the resulting simulations will show mismatch with data and parameters are usually selected for adjustment (tuning) to improve the agreement with data. One option is to use objective tuning methods, such as the genetic algorithm or adjoint method in which many or all of the model parameters are varied simultaneously in order to try and find a best fit solution to data (e.g. Friedrichs et al., 2007; Record et al., 2010; Ward et al., 2010; Xiao and Friedrichs, 2014). The advantage is objectivity, but difficulties include sloppy parameter sensitivities (parameters compensate for each other), different values of model parameters may be similarly consistent with the data (the problem of identifiability), exploration of a huge parameter space may be required and local minima in misfit parameter space can make it difficult to find the true global minimum (Slezak et al., 2010). It is usually the case that models are underdetermined by data anyway (Ward et al., 2010), i.e. there are insufficient data (in terms of absolute amount and/or different types of data) to adequately constrain parameter values. And of course, objective methods require expertise, time and computing resources.

Modellers more often than not carry out parameter adjustment by varying values of chosen parameters one at a time until satisfactory convergence with data is achieved. The skill is in deciding which parameters to vary. In principle, sensitivity analysis can be of help in this regard in that sensitive parameters can be identified and selected for adjustment if they can be justifiably altered (i.e. there is uncertainty regard- 
ing their value). Here, we will demonstrate the use of EMPOWER for model calibration. Parameter sets will be derived for the four stations, BIOTRANS and India in the North Atlantic and the HNLC stations Papa (subarctic North Pacific) and KERFIX (Southern Ocean). The ecosystem model we have presented uses the NPZD structure in combination with up-to-date formulations for key processes such as photosynthesis, grazing and mortality. As such, it has not been previously published and so there is no readily available complete set of parameter values to draw upon. Using our experience, we chose appropriate parameter values from the literature and adjusted others to give a good fit with the data for station BIOTRANS. This result is presented below along with a discussion of how we went about achieving this parameter set. Working from this parameter set, tuning of parameters is then undertaken to fit the other stations to the data.

Station BIOTRANS was previously modelled by Fasham and Evans (1995) and we used this publication as a starting point for the assignment of some of the parameter values (note that we opted for the second of two optimisation solutions in this reference). Other parameters were otherwise assigned values from the literature where possible and/or selected as a best guess. The resulting parameter set, along with adjusted (tuned) values (see below), is shown in Table 3.

Photosynthetic parameters, $V_{P}^{\max }$ (maximum rate) and $\alpha$ (initial slope of the $P-I$ curve) are geographically variable, in part due to temperature (Harrison and Platt, 1986; Cullen, 1990; Platt et al., 1990; Rey, 1991; Marañón and Holligan, 1999; Bouman et al., 2000; Huot et al., 2013). We based parameters $V_{P}^{\max }(0)$ (the maximum rate of photosynthesis at $0^{\circ} \mathrm{C}$ ) and $\alpha$ (initial slope of the $P-I$ curve) on the mean of values for polar waters provided in Table 2 of Rey (1991), i.e. $V_{P}^{\max }(0)=2.5 \mathrm{~g} \mathrm{C}(\mathrm{g} \mathrm{chl})^{-1} \mathrm{~h}^{-1}$ and $\alpha=0.034 \mathrm{gCC}(\mathrm{g} \mathrm{chl})^{-1} \mathrm{~h}^{-1}\left(\mu \mathrm{E} \mathrm{m}^{-2} \mathrm{~s}^{-1}\right)^{-1}$. Similar values were recorded more recently in the Beaufort Sea by Huot et al. (2013). Converting units, param-

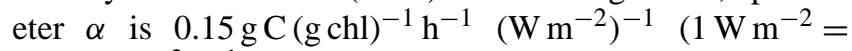
$4.55 \mu \mathrm{E} \mathrm{m}^{-2} \mathrm{~s}^{-1}$, based on the spectral distribution of white light given in Anderson, 1993). Note that photosynthetic parameters are specified per unit phytoplankton biomass expressed as chlorophyll, requiring unit conversion. The Redfield $\mathrm{C}: \mathrm{N}$ molar ratio of 6.625 is the obvious choice to convert between $\mathrm{C}$ and $\mathrm{N}$. Carbon to chlorophyll ratios are more variable and a value of $50 \mathrm{~g} \mathrm{C}(\mathrm{g} \mathrm{chl})^{-1}$ has previously been used in modelling studies (e.g. Fasham et al., 1990). However, $\mathrm{C}$ : chl ratios are known to vary widely in response to ambient conditions. The recent study of Sathyendranath et al. (2009) found that, in the North Atlantic, the ratio typically vary between 50 and $100 \mathrm{~g} \mathrm{C}\left(\mathrm{g} \mathrm{chl}^{-1}\right.$ and so here we use an intermediate value of $75 \mathrm{~g} \mathrm{C}(\mathrm{g} \mathrm{chl})^{-1}$ (parameter $\left.\theta_{\text {chl }}\right)$. Remaining phytoplankton parameters are $k_{N}, 0.85 \mathrm{mmol} \mathrm{N} \mathrm{m}^{-3}$ (Fasham and Evans, 1995), $m_{P}, 0.02 \mathrm{~d}^{-1}$ (Yool et al., 2011, 2013a), and $m_{P 2}, 0.025\left(\mathrm{mmol} \mathrm{N} \mathrm{m}^{-3}\right)^{-1} \mathrm{~d}^{-1}$ (Oschlies and Schartau, 2005).
Zooplankton parameters $I_{\max }$ and $k_{Z}$ were assigned directly from Fasham and Evans (1995) with values of $1.0 \mathrm{~d}^{-1}$ and $0.86 \mathrm{mmol} \mathrm{N} \mathrm{m}^{-3}$ respectively. When it comes to calculating growth, the assimilation efficiency used by Fasham and Evans (1995) is in fact a growth efficiency whereas our use of absorption efficiency (parameter $\beta$ ) is more in keeping with contemporary zooplankton modelling (e.g. see Anderson et al., 2013) and refers to the fraction of material absorbed across the gut. It is multiplied by net production efficiency (parameter $k_{\mathrm{NZ}}$ ) to give growth efficiency. Values of 0.69 and 0.75 were assigned to parameters $\beta$ and $k_{\mathrm{NZ}}$ respectively (Anderson, 1994; Anderson and Hessen, 1995). Zooplankton ought to have a strong grazing preference for phytoplankton and so the preference value (parameter $\varphi_{P}$ ) of 0.12 used by Fasham and Evans (1995) seems unreasonably low. We instead assigned values of 0.67 and 0.33 for parameters $\varphi_{P}$ and $\varphi_{D}$, the same ratio of the equivalent preferences used in Fasham (1993). Thus, if $k_{Z}=1 \mathrm{mmol} \mathrm{N} \mathrm{m}^{-3}$, this implies that the phytoplankton single-prey half-saturation is $1.22 \mathrm{mmol} \mathrm{N} \mathrm{m}^{-3}$ and the detritus single-prey half-saturation constant is $1.75 \mathrm{mmol} \mathrm{N} \mathrm{m}^{-3}$. The implied single-prey halfsaturation constants change to 1.05 and $1.50 \mathrm{mmol} \mathrm{N} \mathrm{m}^{-3}$ respectively when $k_{Z}=0.86 \mathrm{mmol} \mathrm{N} \mathrm{m}^{-3}$. Mortality parameters $m_{Z}$ and $m_{Z 2}$ were assigned values of $0.02 \mathrm{~d}^{-1}$ (Yool et al., 2011, 2013a) and $0.34\left(\mathrm{mmol} \mathrm{N} \mathrm{m}^{-3}\right)^{-1} \mathrm{~d}^{-1}$ (Oschlies and Schartau, 2005) respectively.

Detritus is composed of a range of sinking material including faecal pellets and marine snow of between 5 and several $100 \mathrm{~m} \mathrm{~d}^{-1}$ (Wilson et al., 2008), as well as slow-sinking material that is likely to be remineralised in the upper water column (Riley et al., 2012). A typical sinking rate used in ecosystem models is between 5 and $10 \mathrm{~m} \mathrm{~d}^{-1}$ (e.g, Fasham et al., 1990; Oschlies and Garcon, 1999; Anderson and Pondaven, 2003; Llebot et al., 2010; Kidson et al., 2013). We used a value for $V_{D}$ of $6.43 \mathrm{~m} \mathrm{~d}^{-1}$ (Fasham and Evans, 1995). Note also that the detritus produced by quadratic zooplankton mortality is assumed to be very fast-sinking and is instantly exported from the upper mixed layer. The remineralisation rate of detritus (parameter $m_{D}$ ) was set to $0.06 \mathrm{~d}^{-1}$ (Fasham and Evans, 1995). Finally, parameter $w_{\text {mix }}$ was set to $0.13 \mathrm{~m} \mathrm{~d}^{-1}$ (Fasham and Evans, 1995).

Choices have to be made regarding the settings for calculating daily depth-integrated photosynthesis. A sinusoidal pattern of daily irradiance was set as default for this purpose, with a numeric integration over time of day. A Smith function was chosen as the $P-I$ curve (Eq. 7) as this permits a straightforward analytic depth integral for photosynthesis (Appendix B). Photosynthesis at depth can be vertically integrated analytically when light extinction in the water column is described by Beer's law with a constant coefficient. As default, we use the piecewise Beer's law treatment of Anderson (1993) in which the water column is divided into three depth zones (0-5, 5-23 and $>23 \mathrm{~m})$ and a separate extinction coefficient calculated for each as a function of chlorophyll (Eq. 10). Although this approach is more complicated than 
Table 3. Model parameters. Fitted model solutions for stations BIOTRANS, India, Papa and KERFIX. The initial (unfitted) parameter guesses for BIOTRANS were as for the fitted solution, except that parameters $m_{P}$ and $k Z$ were tuned from initial settings of $0.02 \mathrm{~d}^{-1}$ and $0.86 \mathrm{mmol} \mathrm{N} \mathrm{m}^{-3}$ respectively (see text and footnotes).

\begin{tabular}{|c|c|c|c|c|c|c|}
\hline Parameter & Meaning & Unit & BIOTRANS & India & Papa & KERFIX \\
\hline$V_{P}^{\max }(0) \alpha$ & $\begin{array}{l}\text { max rate photosynthesis } 0^{\circ} \mathrm{C} \\
\text { initial slope of } P-I \text { curve }\end{array}$ & $\begin{array}{l}\mathrm{gC}\left(\mathrm{g} \mathrm{chl}^{-1} \mathrm{~h}^{-1}\right. \\
\mathrm{gC}\left(\mathrm{g} \mathrm{chl}^{-1} \mathrm{~h}^{-1}\right. \\
\left(\mathrm{W} \mathrm{m}^{-2}\right)^{-1}\end{array}$ & $\begin{array}{l}2.5^{\mathrm{a}} \\
0.15^{\mathrm{a}}\end{array}$ & $\begin{array}{l}2.5 \\
0.15\end{array}$ & $\begin{array}{l}1.25^{\mathrm{b}} \\
0.075^{\mathrm{b}}\end{array}$ & $\begin{array}{l}1.25^{\mathrm{b}} \\
0.075^{\mathrm{b}}\end{array}$ \\
\hline$k_{N}$ & half-sat. constant: $N$ uptake & $\mathrm{mmol} \mathrm{N} \mathrm{m}{ }^{-3}$ & $0.85^{\mathrm{c}}$ & 0.85 & 0.85 & 0.85 \\
\hline$m_{P}$ & phyto. mortality (linear) & $d^{-1}$ & $0.015^{\mathrm{d}}$ & 0.015 & 0.015 & 0.015 \\
\hline$m_{P 2}$ & phyto. mortality (quadratic) & $\left(\mathrm{mmol} \mathrm{N} \mathrm{m}{ }^{-3}\right)^{-1} \mathrm{~d}^{-1}$ & $0.025^{\mathrm{e}}$ & 0.025 & 0.025 & 0.025 \\
\hline$I_{\max }$ & zoo. max ingestion rate & $\mathrm{d}^{-1}$ & $1.0^{\mathrm{c}}$ & 1.0 & $1.25^{\mathrm{f}}$ & $2.0^{f}$ \\
\hline$k_{Z}$ & zoo. half-saturation for intake & $\mathrm{mmol} \mathrm{Nm}^{-3}$ & $0.6^{\mathrm{g}}$ & 0.6 & 0.6 & 0.6 \\
\hline$\varphi_{P}$ & grazing preference: $P$ & dimensionless & $0.67^{\mathrm{h}}$ & 0.67 & 0.67 & 0.67 \\
\hline$\varphi_{D}$ & grazing preference: $D$ & dimensionless & $0.33^{\mathrm{h}}$ & 0.33 & 0.33 & 0.33 \\
\hline$\beta_{Z}$ & zoo. absorption efficiency & dimensionless & $0.69^{\mathrm{i}}$ & 0.69 & 0.69 & 0.69 \\
\hline$k_{\mathrm{NZ}}$ & zoo. net production efficiency & dimensionless & $0.75^{\mathrm{j}}$ & 0.75 & 0.75 & 0.75 \\
\hline$m_{Z}$ & zoo. mortality (linear) & $d^{-1}$ & $0.02^{\mathrm{k}}$ & $0.0^{1}$ & 0.02 & 0.02 \\
\hline$m_{Z 2}$ & zoo. mortality (quadratic) & $\left(\mathrm{mmol} \mathrm{N} \mathrm{m}{ }^{-3}\right)^{-1} \mathrm{~d}^{-1}$ & $0.34^{\mathrm{m}}$ & 0.34 & 0.34 & 0.34 \\
\hline$v_{D}$ & detritus sinking rate & $\mathrm{md}^{-1}$ & $6.43^{\mathrm{c}}$ & 6.43 & 6.43 & 6.43 \\
\hline$m_{D}$ & detritus remineralisation rate & $d^{-1}$ & $0.06^{\mathrm{c}}$ & 0.06 & 0.06 & 0.06 \\
\hline$w_{\text {mix }}$ & cross-thermocline mixing & $\mathrm{md}^{-1}$ & $0.13^{\mathrm{c}}$ & 0.13 & 0.13 & 0.13 \\
\hline$\theta_{\mathrm{chl}}$ & $\mathrm{C}$ to chlorophyll ratio & $\mathrm{g} \mathrm{g}^{-1}$ & $75^{\mathrm{n}}$ & 75 & 75 & 75 \\
\hline
\end{tabular}

Source: ${ }^{a}$ mean of values for polar waters provided in Table 2 of Rey (1991); ${ }^{b}$ photosynthetic parameters of HNLC stations halved with respect to BIOTRANS because of iron limitation (see text); ${ }^{\mathrm{c}}$ Fasham and Evans (1995); ${ }^{\mathrm{d}}$ tuned for BIOTRANS; initial guess was $0.02 \mathrm{~d}^{-1}$ (Yool et al. $\left(2011,2013 \mathrm{a}\right.$ ); ${ }^{\mathrm{e}}$ Oschlies and Schartau (2005); ${ }^{\mathrm{f}}$ tuned for HNLC stations (see text); ${ }^{\mathrm{g}}$ tuned for BIOTRANS: initial guess was $0.86 \mathrm{mmol} \mathrm{N} \mathrm{m}^{-3}$ (Fasham and Evans, 1995$)$; ${ }^{\mathrm{h}}$ as for Fasham (1993) but adjusted for different model structure; ${ }^{i}$ Anderson (1994); ${ }^{j}$ Anderson and Hessen (1995); ${ }^{\mathrm{k}}$ Yool et al. (2011, 2013a); ${ }^{1}$ tuned for station India;

${ }^{\mathrm{m}}$ Oschlies and Schartau (2005); ${ }^{\mathrm{n}}$ Sathyendranath et al. (2009).

using a single extinction coefficient, it is easily justified a priori given the improved representation of light attenuation and its impact on predicted primary production (Anderson, 1993). Model sensitivity to these various assumptions regarding the calculation of light attenuation and photosynthesis will be examined in Sect. 4.3, including an assessment of the performance of the algorithms of Evans and Parslow (1985) and Anderson (1993).

The model was run for 5 years, by which time it generates a repeating annual cycle of plankton dynamics. The last year of simulation for station BIOTRANS, with initial parameter settings as described above, is compared to data for chlorophyll and nitrate in Fig. 10. Nitrate (model DIN) is predicted remarkably well using these default parameter settings, whereas the predicted seasonal cycle of chlorophyll shows a poorer match with data. The peak of the spring bloom is more than double that observed and post-bloom chlorophyll is also consistently elevated (by approximately $0.2 \mathrm{mg} \mathrm{m}^{-3}$ ) relative to observations (Fig. 10). Parameter adjustment is therefore desirable in order to improve the fit with data.

\subsection{Model calibration}

Many modelers go about parameter adjustment on a trialand-error basis, making ad hoc changes to parameters and observing the outcome. A more structured way of going
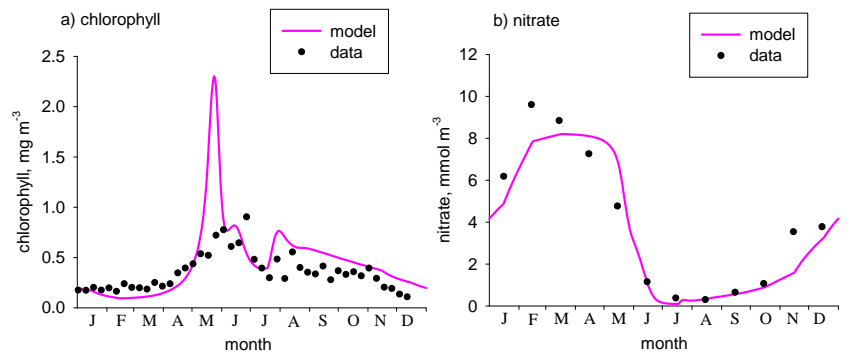

Figure 10. Simulation for station BIOTRANS using first-guess parameters compared to data (year 2002) for (a) chlorophyll and (b) nitrate.

about this is to undertake a systematic sensitivity analysis of parameters and then, informed by this analysis, choose which parameters to vary. We use EMPOWER to demonstrate this practice here. Three variables were selected as simple measures of model mismatch with data: minimum DIN encountered during the seasonal cycle, $N_{\min }$, which is a logical choice because it is desirable to correctly predict DIN drawdown during the spring period, maximum chlorophyll at the peak of the spring bloom, $\mathrm{chl}_{\max }$ and the average summer chlorophyll between days 150 and $300, \mathrm{chl}_{\mathrm{av}}$. Values of these three quantities, as outputs from the run shown in Fig. 10, were $0.093 \mathrm{mmol} \mathrm{N} \mathrm{m}^{-3}$ for $\mathrm{N}_{\min }$ and 2.30 and 

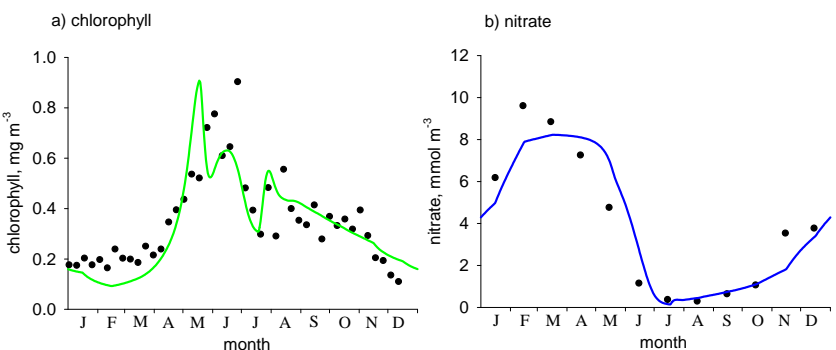

Figure 11. Simulation for station BIOTRANS after parameter tuning (see text): (a) chlorophyll, (b) nitrate.

$0.58 \mathrm{mg} \mathrm{chl} \mathrm{m}^{-3}$ for $_{\mathrm{chl}} \mathrm{max}_{\max }$ and $\mathrm{chl}_{\mathrm{av}}$ respectively. Model parameters were varied $\pm 10 \%$ and the change in these variables quantified in terms of normalised sensitivity:

$S(p)=\frac{\left(W(p)-W_{S}\right) / W_{S}}{\left(p-p_{S}\right) / p_{S}}$,

where $W_{S}$ is the value of a given variable (in this case $N_{\min }$, $\mathrm{chl}_{\max }$ or $\mathrm{chl}_{\mathrm{av}}$ ) for the standard parameter set with parameter value $p_{S}$, and $W(p)$ is the value when the parameter is given value $p$. Results are shown in Table 4, ordered high to low for sensitivity of $\mathrm{chl}_{\max }$.

The requirement for improving the model fit is to decrease $\mathrm{chl}_{\max }$ and, to a lesser extent, decrease chl $\mathrm{av}_{\mathrm{av}}$ also. Looking at Table 4, chl $l_{\max }$ and $\mathrm{chl}_{\mathrm{av}}$ are together sensitive to zooplankton parameters, notably $k_{Z}, I_{\max }$ and $\beta_{Z}$. In contrast, $\mathrm{chl}_{\max }$ is sensitive to phytoplankton mortality, $m_{P}$, whereas $\mathrm{chl}_{\mathrm{av}}$ is not. The initial guess for $k_{Z}$ of $1.0 \mathrm{mmol} \mathrm{N} \mathrm{m}^{-3}$ may be somewhat high, e.g. separate values of 0.8 and $0.3 \mathrm{mmol} \mathrm{N} \mathrm{m}^{-3}$ were used for micro- and mesozooplankton in the model of Yool et al. (2011, 2013a). Values for $k_{Z}$ lower than $1.0 \mathrm{mmol} \mathrm{N} \mathrm{m}^{-3}$ have also been used in other models, e.g. values of 0.75 and $0.8 \mathrm{mmol} \mathrm{N} \mathrm{m}^{-3}$ were used by Anderson and Pondaven (2003) and Llebot et al. (2010) respectively. Mortality parameters such as $m_{P}$ are poorly known and an easy choice for modellers when it comes to parameter adjustment. We varied parameters $k_{Z}$ and $m_{P}$ and were able to achieve a good fit to the data with $k_{Z}=0.6 \mathrm{mmol} \mathrm{N} \mathrm{m}^{-3}$ and $m_{P}=0.015 \mathrm{~d}^{-1}$ (Fig. 11). The predicted overwinter chlorophyll is somewhat too low but this is a common feature of slab-type models. The mismatch can be improved by removing the linear phytoplankton mortality term (i.e. setting $m_{P}=0$; see Sect. 4.4 and discussion therein). A further consideration is that phytoplankton may adjust their $\mathrm{C}: \mathrm{chl}$ ratio in winter to mitigate the effect of the low light intensities that they experience. We consider removing this mortality term unrealistic. It is no good getting the right result for the wrong reasons and so chose to keep phytoplankton mortality unchanged.

The associated seasonal cycles of $P, Z$ and $D$, along with primary production, phytoplankton grazing and mortality are shown in Fig. 12. Phytoplankton escape grazing in control in April and early May with the peak of the bloom occurring on
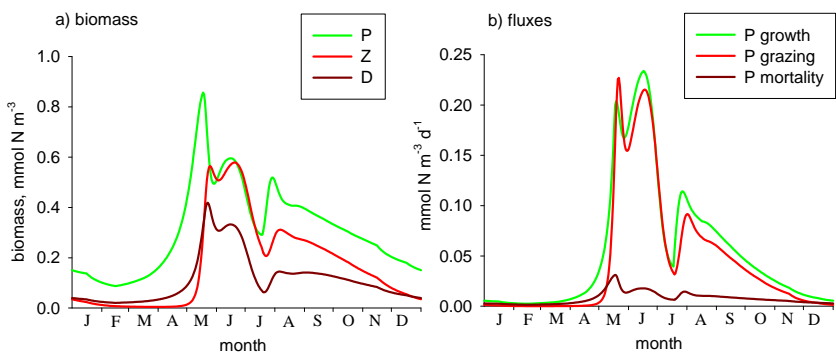

Figure 12. Predicted state variables and fluxes for the station BIOTRANS simulation: (a) $P, Z$ and $D$ and (b) phytoplankton growth, grazing and non-grazing mortality.

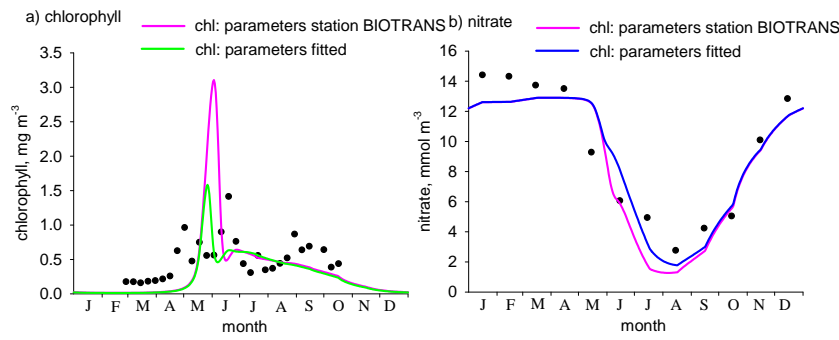

Figure 13. Simulations for station India: (a) chlorophyll, (b) nitrate. Data are for year 1998.

day 137. Zooplankton catch up a week later. Primary production remains relatively high over summer, but tightly coupled to grazing which is sufficient to keep phytoplankton biomass in check. Nutrient drawdown continues after the peak of the bloom with maximum depletion occurring in July.

It might be expected that station India is simulated accurately with the same parameter values as those of station BIOTRANS because of their relatively close proximity in the northern North Atlantic Ocean. In fact, the predicted spring bloom is rather high, approximately double the maximum in the observations for year 1998 (Fig. 13), although not outwith what is seen in the multi-year data (Fig. 9). An improved fit is easily achieved by setting $m_{Z}=0$, i.e. removing the linear zooplankton mortality term (Fig. 13). Other models, e.g. Fasham (1993), have similarly not included a linear zooplankton loss term.

The two HNLC stations can be expected to require alternative parameterisations to the two North Atlantic stations because of their different food web structure. In contrast to the diatom spring bloom in the northern North Atlantic, iron-limited HNLC systems favour small phytoplankton which are tightly coupled to microzooplankton grazers (Landry et al., 1997, 2011), "grazer controlled phytoplankton populations in an iron-limited ecosystem" (Price et al., 1994). Low growth rate of phytoplankton may be expected relative to the North Atlantic because of iron limitation. Parameters $V_{P}^{\max }(0)$ and $\alpha$ may typically decrease by $50 \%$ relative to iron-replete conditions (Alderkamp et al., 2012). For stations Papa and KERFIX, 


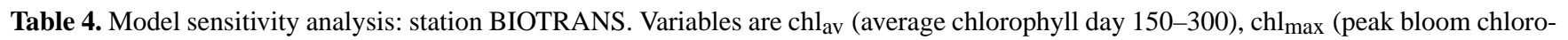
phyll) and $N_{\min }$ (minimum nitrate during seasonal drawdown). Parameters ranked according to sensitivity to chl max $_{\text {. }}$.

\begin{tabular}{lrrrrrr}
\hline Parameter & $\operatorname{chl}_{\mathrm{av}} S(p)+10 \%$ & $\mathrm{chl}_{\mathrm{av}} S(p)-10 \%$ & $\mathrm{chl}_{\max } S(p)+10 \%$ & $\operatorname{chl}_{\max } S(p)-10 \%$ & $N_{\min } S(p)+10 \%$ & $N_{\min } S(p)-10 \%$ \\
\hline$I_{\max }$ & -0.55 & -0.83 & -1.10 & -1.27 & 0.60 & 0.58 \\
$k_{Z}$ & 0.92 & 0.90 & 1.04 & 1.20 & -0.81 & -1.09 \\
$\beta_{Z}$ & -0.29 & -0.50 & -1.02 & -1.18 & 0.29 & 0.32 \\
$k_{\mathrm{NZ}}$ & -0.53 & -0.75 & -1.02 & -1.17 & -0.11 & -0.10 \\
$m_{P}$ & 0.01 & -0.03 & 0.62 & 0.72 & 0.07 & 0.07 \\
$\alpha$ & -0.05 & -0.16 & -0.70 & -0.60 & -0.53 & -0.68 \\
$\varphi_{P}$ & -0.40 & -0.47 & -0.51 & -0.55 & 0.44 & 0.45 \\
$m_{Z}$ & 0.07 & 0.06 & 0.49 & 0.49 & -0.07 & -0.06 \\
$V_{P}^{\max }(0)$ & -0.08 & -0.12 & -0.20 & -0.16 & -0.63 & -0.81 \\
$k_{N}$ & 0.00 & -0.01 & 0.09 & 0.10 & 1.06 & 1.05 \\
$m_{Z 2}$ & 0.27 & 0.28 & 0.09 & 0.09 & -0.27 & -0.32 \\
$m_{P 2}$ & -0.02 & -0.02 & -0.07 & -0.06 & 0.05 & 0.05 \\
$m_{D}$ & 0.06 & 0.06 & 0.01 & 0.01 & 0.11 & 0.11 \\
$w_{\operatorname{mix}}$ & 0.07 & 0.07 & 0.01 & 0.01 & 0.65 & 0.67 \\
$v_{D}$ & -0.04 & -0.04 & 0.01 & 0.01 & -0.13 & -0.16 \\
\hline
\end{tabular}
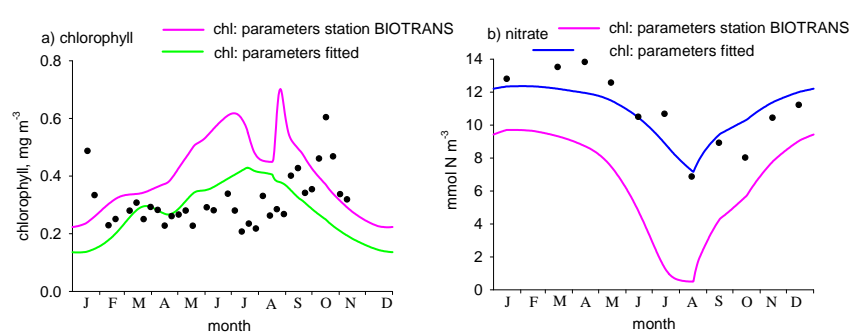

Figure 14. Simulations for station Papa before and after parameter tuning: (a) chlorophyll, (b) nitrate. Data are for year 2007.

we therefore assigned $V_{P}^{\max }(0)=1.25 \mathrm{gC}(\mathrm{g} \mathrm{chl})^{-1} \mathrm{~h}^{-1}$ and $\alpha=0.075 \mathrm{~g} \mathrm{C}\left(\mathrm{g} \mathrm{chl}^{-1} \mathrm{~h}^{-1}\left(\mathrm{~W} \mathrm{~m}^{-2}\right)^{-1}\right.$. In addition, high maximum grazing rates may be expected because of the small size structure of the plankton assemblage. If grazing is dominated by microzooplankton, maximum grazing rate (parameter $I_{\max }$ ) may be as high as $2.0 \mathrm{~d}^{-1}$ (Mongin et al., 2006). We achieved a good fit to data with $I_{\max }=$ $1.25 \mathrm{~d}^{-1}$ (Fig. 14). A similar exercise was carried out for station KERFIX. Using the same parameter set as for station Papa, predicted chlorophyll was too high (by approximately $0.05 \mathrm{mg} \mathrm{m}^{-3}$ ) during the austral summer (Fig. 15). If $I_{\max }$ is further increased to $2.0 \mathrm{~d}^{-1}$, a reasonable fit to the chlorophyll data is achieved (Fig. 15). The predicted end-of-year increase in chlorophyll arrives a month or two too early, but this may be a consequence of the imposed climatological cycle of mixed layer depth. Predicted nitrate is somewhat too low (by about $4 \mathrm{mmol} \mathrm{m}^{-3}$ ) if the BIOTRANS parameters are used but is markedly improved with the adjusted parameters.
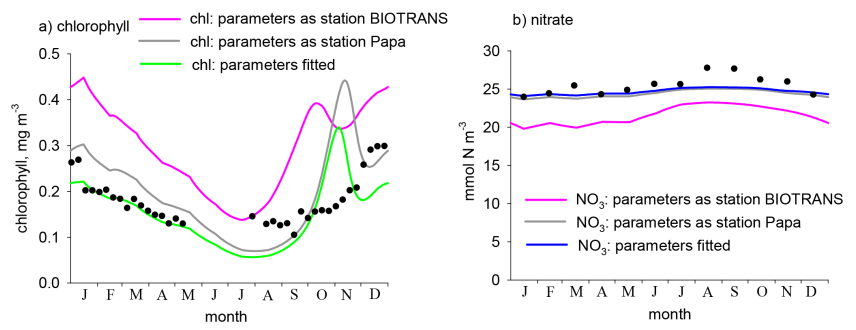

Figure 15. Simulations for station KERFIX before and after parameter tuning (see text for details): (a) chlorophyll, (b) nitrate. Data are for year 2006.

\subsection{Sensitivity to photosynthesis algorithm}

Structural sensitivity analysis is performed to assess model sensitivity to the different assumptions for calculating daily depth-integrated photosynthesis. The best-fit simulation for station BIOTRANS presented above (Fig. 11) is used as the baseline for comparison, although we will comment on sensitivity for other stations also. Default settings in the baseline simulation were a numerical time integration (over the day), a Smith function for the $P-I$ curve, and a sinusoidal pattern of daily irradiance with the piecewise application of Beer's law (Eq. 10; Anderson, 1993) for light attenuation in the water column.

The first sensitivity test involved changing the $P-I$ curve from a Smith function (Eq. 7) to an exponential function (Eq. 8). Predicted seasonal cycles for chlorophyll and nitrate at station BIOTRANS are shown in Fig. 16. Results changed little with respect to the baseline simulation, the only noticeable difference being the magnitude of the spring bloom which was about $0.2 \mathrm{mg} \mathrm{m}^{-3}$ greater when using the exponential $P-I$ curve. Similar insensitivity was seen when using the exponential $P-I$ curve for simulating stations India, Papa 

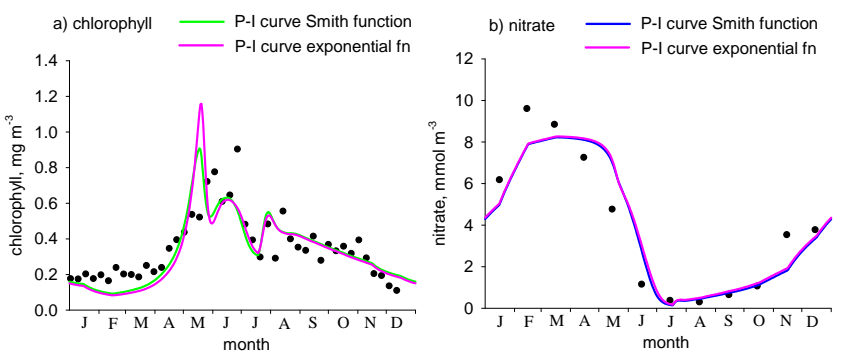

Figure 16. Simulations for station BIOTRANS showing sensitivity to choice of $P-I$ curve: (a) Smith function (standard run), (b) exponential function.
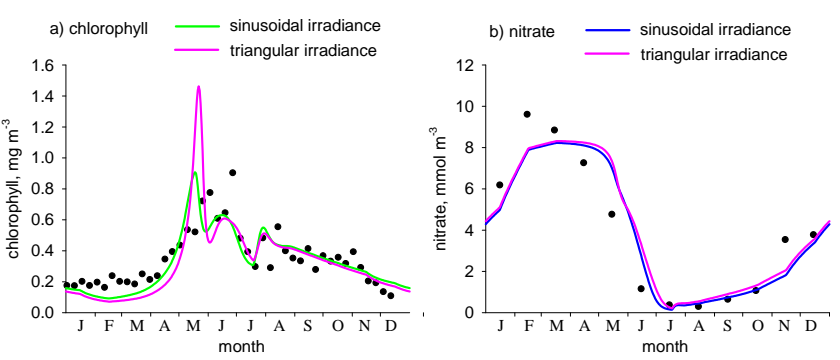

Figure 17. Simulations for station BIOTRANS showing sensitivity to choice of diel variation in irradiance: (a) sinusoidal (standard run), (b) triangular.

and KERFIX (results not shown). It is perhaps unsurprising that the model shows minimal sensitivity to choice of $P-I$ curve as the shapes of the two curves are similar.

Reverting to the Smith function as the chosen $P-I$ curve, model predictions were next compared for simulations using sinusoidal versus triangular irradiance (Fig. 17). Once again, the difference between the two simulations is relatively minor. A larger spring bloom (approx. $0.5 \mathrm{mg} \mathrm{m}^{-3}$ ) is seen when using the triangular assumption. Irradiance is underestimated relative to the sinusoidal pattern (Fig. 6) leading to lower primary production over winter, decoupling from zooplankton and a larger spring bloom. It is worth noting that the sensitivity shown to choice of irradiance pattern is at least as great as that for the choice of $P-I$ curve but has generally received much less attention in the literature.

Model sensitivity of predicted primary production to the equations describing light attenuation in the water column was previously highlighted by Anderson (1993), although without extending to analysis using full ecosystem models. Model predictions for the two choices for light attenuation (simple Beer's law, Eq. 9, versus piecewise Beer's, Eq. 10) are shown in Fig. 18, for all four stations. Whereas chlorophyll shows little change when switching between the two routines, predicted $\mathrm{NO}_{3}$ exhibits markedly greater drawdown when using the simple Beer's law, especially for station India where concentrations reached near zero by the end of June. The difference between the simulations can be understood by
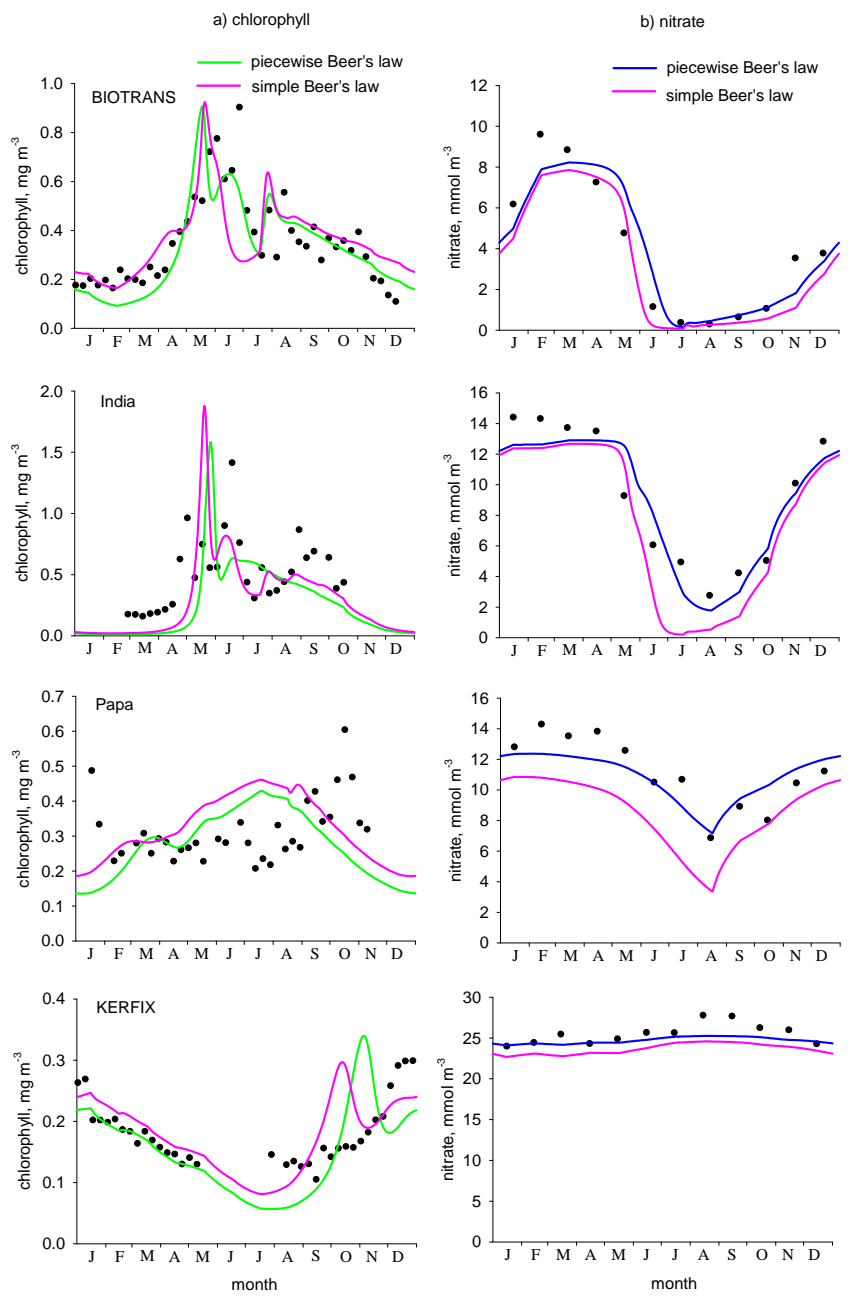

Figure 18. Model simulations for all four stations showing sensitivity to choice of method for calculating light attenuation in the water column: (a) piecewise Beer's law (Eq. 10), (b) simple Beer's law (Eq. 9).

comparing $k_{\mathrm{PAR}}$ as a function of phytoplankton concentration for the two algorithms (Fig. 19). The single Beer's law of Eq. (9) predicts a modest increase in $k_{\mathrm{PAR}}$ from $0.04 \mathrm{~m}^{-1}$ at zero phytoplankton to $0.1 \mathrm{~m}^{-1}$ at $P=1 \mathrm{mmol} \mathrm{N} \mathrm{m}^{-3}$. The main difference with the piecewise Beer's law is the much greater light extinction in the upper $5 \mathrm{~m}$ of the water column, with $k_{\mathrm{PAR}}$ of $0.13 \mathrm{~m}^{-1}$ at $P=0 \mathrm{mmol} \mathrm{N} \mathrm{m}^{-3}$ increasing to $0.23 \mathrm{~m}^{-1}$ at $P=1 \mathrm{mmol} \mathrm{N} \mathrm{m}^{-3}$. A lesser rate of light attenuation using the simple Beer's law leads to greater penetration of light into the water column, higher photosynthesis and greater predicted drawdown of $\mathrm{NO}_{3}$.

Finally, there is the option to use the routines of Evans and Parslow (1985) and Anderson (1993) to calculate daily depth-integrated photosynthesis, without recourse to using numerical integration over time. Evans and Parslow used a Smith function for photosynthesis in combination with a triangular pattern of daily irradiance. This corresponds exactly 


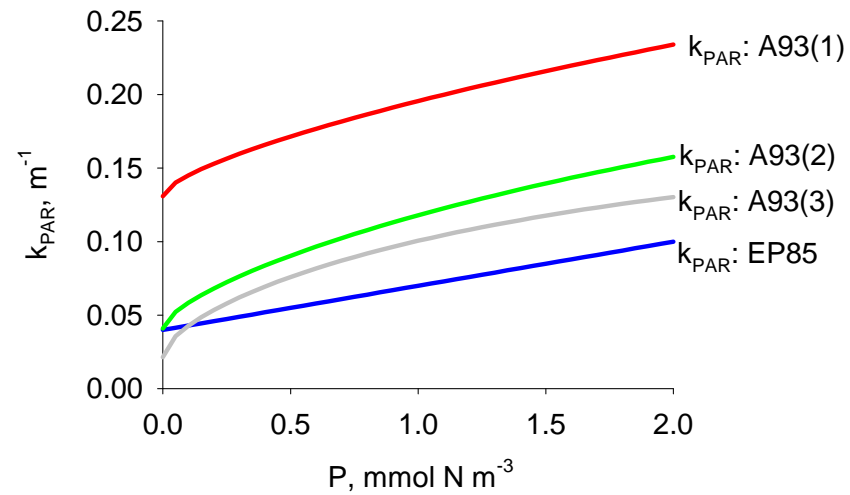

Figure 19. Light attenuation as predicted by Evans and Parslow (1985; EP85) and for the three layers (0-5, 5-23, > $23 \mathrm{~m}$; 1, 2, 3 respectively) in Anderson (1993; A93), as a function of phytoplankton concentration.

to the simulation in Fig. 17 for triangular irradiance. Thus, running the model using the Evans and Parslow equations (Appendix C) produces a result indistinguishable from the numerical simulation. Matters are not so simple when using the Anderson (1993) equations to calculate daily depthintegrated photosynthesis. The assumptions here are an exponential $P-I$ curve and sinusoidal light, corresponding to the exponential $P$ - $I$ curve simulation in Fig. 16. But there is the additional assumption that parameter $\alpha$, in addition to $k_{\text {PAR }}$, is spectrally dependent and varies in the water column. Thus, running the model with both light attenuation and photosynthesis calculated as in Anderson (1993) gives rise to different simulations for the four stations, especially India where there is no bloom (Fig. 20). It is noticeable that, when using the method of Anderson (1993), primary production is higher over winter, a result of elevated $\alpha$, giving rise to an earlier spring chlorophyll bloom and greater drawdown of nitrate.

\subsection{Mortality terms}

The model includes two mortality terms, linear and quadratic, for each of phytoplankton and zooplankton. This approach has previously been used in other models (e.g. Yool et al., 2011, 2013a), giving maximum flexibility. The obvious question is whether all four terms are actually needed. As a simple structural sensitivity analysis, we removed each of the four mortality terms in turn and show the impact on the predicted seasonal cycles of chlorophyll and nitrate for all four stations. The model is relatively insensitive to the phytoplankton mortality terms although setting $m_{P}=0$ (i.e. removal of the linear term) promoted net phytoplankton growth over winter, increasing coupling to zooplankton grazers and giving rise to smaller phytoplankton blooms at stations BIOTRANS and India in spring (Fig. 21). Predicted seasonality in $\mathrm{NO}_{3}$ drawdown was barely affected by phytoplankton mortality parameters. It seems hard to justify that loss rates should go to near zero at low population densities
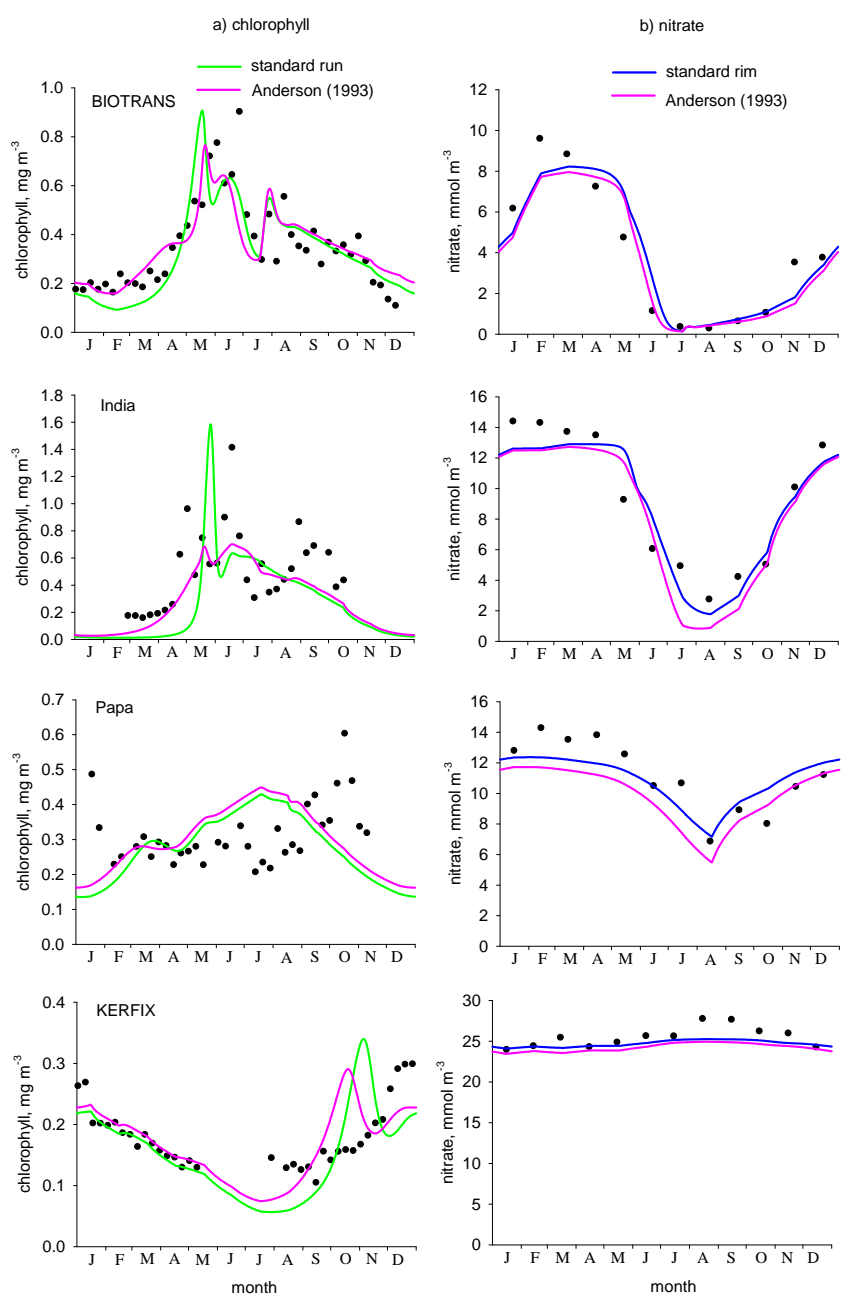

Figure 20. Simulations for all four stations comparing methods for calculating daily depth-integrated photosynthesis, standard run (numeric integration) and the algorithm of Anderson (1993) which is an empirical approximation of a full spectral model: (a) chlorophyll, (b) nitrate

(the consequence of using a quadratic term only) because all organisms have metabolic requirements. Nearly all marine ecosystem models do, therefore, include a linear term for density-independent phytoplankton mortality and, for our baseline simulation (Sect. 4.2), we chose to keep this term on a purely conceptual basis. Given deep mixing, it is surprising that phytoplankton biomass, as seen in the data, is maintained over winter in high-latitude waters. The reasons why this is so remain a matter of conjecture with candidate theories including cyclic motion associated with convective mixing (Huisman et al., 2002; Backhaus et al., 2003), and phytoplankton motility or buoyancy to remain near the ocean surface (see Ward and Waniek, 2007, and references therein). The slab model has difficulty dealing with this issue but there is no evidence that this seriously compromises results when it comes to the predicted timing and magnitude of the spring 

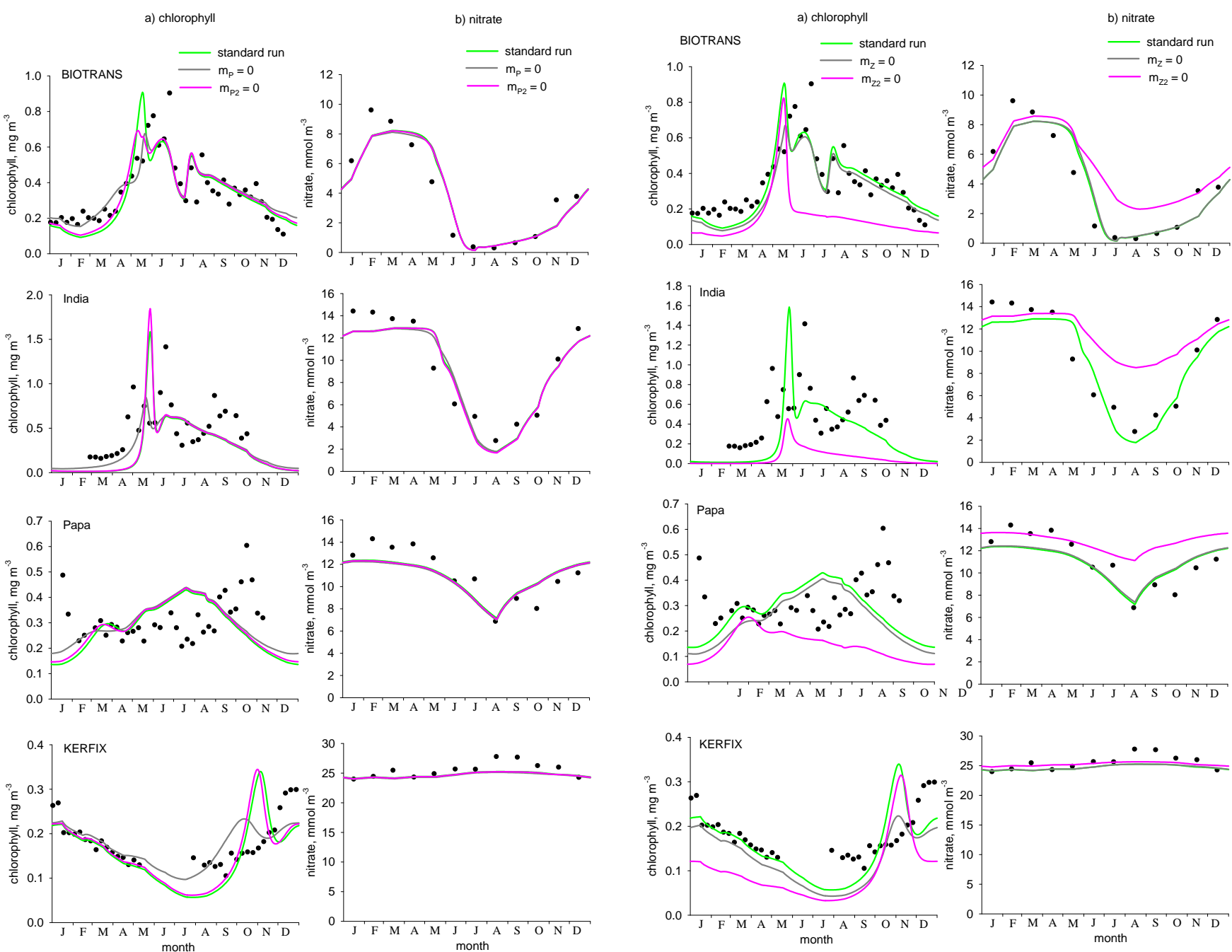

Figure 21. Simulations for all four stations showing model sensitivity to phytoplankton mortality. Parameters $m_{P}$ (linear mortality) and $m_{P 2}$ (quadratic mortality) were set to zero in turn. (a) Chlorophyll, (b) nitrate.

bloom and associated ecosystem dynamics later in the year. In contrast to the representation of linear mortality, many models do not include a non-linear phytoplankton mortality term. Removing it only caused minor changes to model predictions (Fig. 21) and so it may not be necessary.

In contrast to the phytoplankton results, removing the linear zooplankton mortality term had relatively little impact on model predictions, whereas removal of the quadratic term did, for all four stations (Fig. 22). Removal of quadratic mortality resulted in phytoplankton levels decreasing by as much as $50 \%$ which is unsurprising since more zooplankton means more grazing. Perhaps less obvious is the result that removal of quadratic closure resulted in similarly large changes in predicted post-bloom nitrate levels. Predation-related losses, the quadratic term, were assumed to be instantly exported and thereby lost from the surface mixed layer of the model.
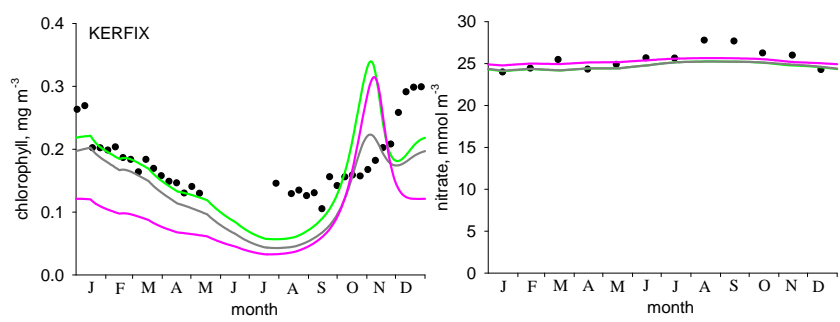

Figure 22. Simulations for all four stations showing model sensitivity for zooplankton mortality. Parameters $m_{Z}$ (linear mortality) and $m_{Z 2}$ (quadratic mortality) were set to zero in turn. (a) Chlorophyll, (b) nitrate.

Thus, when these losses are set to zero (parameter $m_{Z 2}=0$ ), nitrate drawdown is significantly diminished because, instead of being instantly exported, zooplankton quadratic mortality is allocated to sinking detritus, part of which is remineralised in the mixed layer. As was noted by Fulton et al. (2003b), quadratic closure of the upper trophic level in the trophic web tends to be a successful way of closing the web. Overall, the work highlights the need for careful consideration of the parameterisation of closure in models, including the fate of material thereof.

\section{Discussion}

Marine ecosystem modelling is somewhat of a black art regarding decisions about what state variables to include and how to mathematically represent key processes such as pho- 
tosynthesis, grazing and mortality, as well as allocating suitable parameter values. The proliferation of complexity in models has only served to increase the plethora of formulations and parameterisations available to choose from. The complex ecosystem models that have come to the fore in recent years include, for example, any number of plankton functional types, multiple nutrients, dissolved organic matter and bacteria, etc. (e.g. Blackford et al., 2004; Moore et al., 2004; Le Quéré et al., 2005). Simulations are often carried out within computationally demanding 3-D general circulation models (GCMs) and, of course, the realism in ocean physics thus gained is to be welcomed. The caveat is, however, that improvements in prediction can only be achieved if the biological processes of interest can be realistically characterised (Anderson, 2005). The key is, as described above, to undertake extensive analysis of ecosystem model performance and we propose that the use of a simple slab physical framework of the type used in EMPOWER is ideal in this regard. The pioneers of the field such as Riley, Steele and Fasham employed slab physics to test their models, trying out different formulations and parameterisations, just to see what would happen (Anderson and Gentleman, 2012). The simplicity afforded by using a zero-dimensional slab physics framework provides an ideal playground for familiarisation with ecosystem models, allowing for a multiplicity of runs and ease of analysis. It is by following this approach that the user develops an intuitive understanding of the complex nonlinear interdependencies of the model equations, a precursor to making predictions with confidence.

Here, we have presented an efficient plankton modelling testbed, EMPOWER-1.0, coded in the freely available language R. It provides a readily available and easy to use tool for thoroughly evaluating ecosystem model structure, formulations and parameterisations by coupling the ecosystem dynamics to a simplified representation of the physical environment. EMPOWER has several advantages in that it is fast, easy to run, its results are straightforward to analyse and, last but by no means least, the code is transparent and easily adapted to incorporate new formulations and parameterisations. As such, the main purpose of EMPOWER is to provide an ecosystem model testbed that allows users to fully familiarise themselves with their models, allowing them to subsequently be incorporated with greater confidence into 1$\mathrm{D}$ or 3-D models, as required. It may be that some amount of reparameterisation is required when transferring the model ecosystem between physical codes (from slab to 1-D or 3-D), but this ought usually to be minimal in extent and will itself be greatly informed by the previous slab modelling work. Much better this approach, than starting out from scratch using computationally expensive and time-consuming 1-D or 3-D codes to undertake ecosystem model parameterisation.

Bearing in mind Steele's two-layer sea, the first slab model of its kind (Sect. 2), it is worth noting that simple ocean box models are akin to slab models in terms of physical structure but, whereas slab models usually are usually set up for point locations in the ocean, box models represent spatial areas (e.g. ocean basins or the global ocean). A mixed layer or euphotic zone is positioned above a deep ocean layer, with mixing between the two but usually without a seasonally changing mixed layer depth. Tyrrell (1999), for example, used a global ocean box model to study the relative influences of nitrogen and phosphorus on oceanic primary production. Box models were likewise used by Chuck et al. (2005) to study the ocean response to atmospheric carbon emissions over the 21 st century. Slab models, including EMPOWER, effectively convert to simple box models if the seasonality of mixed layer depth is switched off. Without a seasonally varying MLD, box models have limited capacity to capture seasonal plankton dynamics because of the role played by MLD in mediating the light and nutrient environment experienced by phytoplankton. Our results (Figs. 18-20) demonstrate sensitivity to accurate representation of the submarine light field (i.e. equations describing light attenuation in the water column).

In order to demonstrate the utility of EMPOWER, we carried out both a parameter tuning exercise and a structural sensitivity analysis, the latter examining the equations for calculating daily depth-integrated photosynthesis and mortality terms for both phytoplankton and zooplankton. In the parameter tuning exercise, a simple NPZD model, broadly based on the ecosystem model of Fasham and Evans (1995), was fitted to data (seasonal cycles) for chlorophyll and nitrate at four stations: BIOTRANS $\left(47^{\circ} \mathrm{N}, 20^{\circ} \mathrm{W}\right)$, India $\left(60^{\circ} \mathrm{N}, 20^{\circ} \mathrm{W}\right)$, Papa $\left(50^{\circ} \mathrm{N}, 145^{\circ} \mathrm{W}\right)$ and KERFIX $\left(50^{\circ} 40^{\prime} \mathrm{S}, 68^{\circ} 25^{\prime} \mathrm{E}\right)$. Formal parameter sensitivity analysis was carried out, highlighting which parameters phytoplankton stocks and nitrate drawdown are sensitive to. The model was successfully tuned to all four stations, the two HNLC stations (Papa and KERFIX) requiring different parameterisations, notably a halving of photosynthetic parameters (acting as a proxy for iron limitation) relative to the North Atlantic sites.

Our parameterisation of the different stations highlighted the somewhat ad hoc process that most modellers go through when assigning parameter values. Some parameters were set directly from the results of observation and experiment. More often than not, however, we followed the "path of least resistance" when assigning parameters, namely to simply select values from previously published modelling studies. Equations for processes such as photosynthesis, grazing and mortality were likewise selected "off the shelf" from the published literature. Previous publication does not, of course, guarantee that equations or parameter values are necessarily best suited for a particular modelling application. Moreover, it is all too easy for less than ideal, even dysfunctional, formulations to become entrenched within the discipline and used in common practice (Anderson and Mitra, 2010). Parameter tuning is almost inevitable in order to ensure satisfactory agreement with data and we have shown how rigorous sensitivity analysis can help in this regard. Of course, even with a table of parameter sensitivities, there is still a consid- 
erable subjective element to choosing which parameters to adjust. The most sensitive parameters should be selected, but the degree of uncertainty in parameter values is an additional consideration. It is no good tuning a sensitive parameter if its value is already well known from observation and experiment.

A necessary complement when ensuring that models show acceptable agreement with data is to remember that it is important that the theories and assumptions underlying the conceptual description of models are correct or, at least, not incorrect (Rykiel Jr., 1996). Indeed, it is the conceptual realisation of models that in many ways poses the greatest challenge, requiring expertise and practice to overcome observational or experimental lacunae (Tsang, 1991). Subsequent to the parameter tuning exercise, we studied the sensitivity of simulation results to chosen formulations for depthintegrated photosynthesis and both phytoplankton and zooplankton mortality. In the case of the photosynthesis calculation, some aspects showed relatively low sensitivity, namely the choice of $P-I$ curve and whether to assume a triangular or sinusoidal pattern of irradiance throughout the day. In contrast, the way in which light attenuation in the water column is calculated showed marked sensitivity. Using a simple Beer's law (Eq. 9) attenuation coefficient throughout the water column is clearly oversimplified because the spectral properties of irradiance vary with depth. Moving to a piecewise Beer's law (Eq. 10), with separate attenuation coefficients for depth ranges 0-5, 5-23 and > $23 \mathrm{~m}$ (Anderson, 1993), led to more rapid light attenuation near the ocean surface. Depth-integrated photosynthesis declined accordingly, delaying the onset of the spring bloom and reducing its magnitude, along with drawdown of nutrient. The difference is in part due to parameter values, rather than the inherent difference in the equations. Additional sensitivity analysis and parameter tuning could be used to investigate this further but in fact such an analysis was undertaken by Anderson (1993), who showed that no amount of parameter tuning can adequately account for the fact that attenuation will vary with depth, and cannot be assumed to be constant, because of the spectral properties of the irradiance field. Given the above, we conclude that the use of the Evans and Parslow (1985) algorithm to calculate daily depth-integrated photosynthesis, as has been the choice of many previous studies (Table 1), is easily justified, at least for the stations we examined, given the relative insensitivity to choice of $P-I$ curve and choice of triangular versus sinusoidal irradiance. Superior predictions are likely, however, if this algorithm is used in conjunction with the piecewise parameterisation of light attenuation (Anderson, 1993; Eq. 10) rather than a simple Beer's law with fixed attenuation throughout the mixed layer (Eq. 9).

When it comes to biogeochemical modelling studies in GCMs, it is possible that all manner of different methods are used to calculate light attenuation in the water column and resulting photosynthesis. Methodologies are often not reported in full within published texts, the assumption being that they are in some way routine and straightforward and that, perhaps, the models are insensitive to this choice. Consider, for example, the MEDUSA-2.0 (Model of Ecosystem Dynamics, nutrient Utilisation, Sequestration and Acidification) model (Yool et al., 2013a), published within Geoscientific Model Development and afforded a detailed description of equations and chosen parameter values. Despite this level of detail, the model's calculation of light attenuation is largely overlooked and the reader is instead summarily directed to the LOBSTER model (Levy et al., 2001). This divides light into two wavebands, "red" and "green-blue", that are attenuated separately by seawater, and a Smith function (Eq. 7) is used to calculate photosynthesis. The published description omits a number of key details (although the model code was supplied), for instance that there is a 50:50 division of light between the two wavebands at the ocean surface, that the photosynthetically active fraction is 0.43 of total irradiance, that extinction coefficients for the two wavebands are a function of chlorophyll and that photosynthesis is calculated within each model layer (the model uses fixed layer depths, with 13 layers in the upper $100 \mathrm{~m}$ ) as a function of average light within the layer.

As a point of interest, we ran our model for all four stations again, this time using the MEDUSA-2.0 method of light attenuation and a Smith function for the $P-I$ curve (see Appendix $\mathrm{E}$ for details of the parameterisation of light attenuation). The calculation included replication of the layer structure within the GCM in order to achieve a fair comparison. Results (not shown) were remarkably close to the baseline, fitted simulations for each station. In the case of station BIOTRANS, the peak of the spring phytoplankton bloom using the MEDUSA light parameterisation was only $0.7 \mathrm{mg} \mathrm{chl} \mathrm{m}^{-3}, 0.2 \mathrm{mg} \mathrm{m}^{-3}$ less than that in the standard run, but otherwise predicted seasonal cycles of chlorophyll and nitrate that were almost identical for the two simulations. Likewise, the predicted chlorophyll and nitrate changed little at stations India and Papa, whereas at KERFIX nitrate drawdown was slightly greater, approximately $0.5 \mathrm{mmol} \mathrm{N} \mathrm{m}^{-3}$, when using the MEDUSA light parameterisation. The similarity between simulations using the two different approaches to light attenuation occurs because, remarkably, calculated light attenuation using the two red and green wavebands (MEDUSA) differs little from that using the Anderson (1993) piecewise Beer's law. Here, in a nutshell, is a classic example of the utility of EMPOWER. This result should alert GCM modellers to the fact that nearidentical results can be generated for light attenuation in the water column using these two contrasting sets of equations and a choice can be made as to which is most suitable for implementation based on computational efficiency. From a theoretical point of view, the result is also interesting. The equations of Anderson (1993) are an empirical approximation of the full spectral model of Morel (1988) which divided PAR into 61 wavebands. It would appear that this model can be stripped down to just two wavebands, red and green, with- 
out serious degradation in accuracy when it comes to predicting light attenuation.

We also used EMPOWER to undertake an analysis of model sensitivity to the presence/absence of linear and nonlinear mortality terms for phytoplankton and zooplankton. Whereas the use of linear phytoplankton mortality terms is commonplace in models (e.g. Anderson and Williams, 1998; Oschlies and Schartau, 2005; Salihoglu et al., 2008; Llebot et al., 2010), we investigated the performance of an additional quadratic phytoplankton mortality term. This term is intended to represent loss processes that scale with phytoplankton biomass that are not already accounted for in the model. Given that both self-shading and grazing are explicitly modelled, we considered the quadratic term to represent mortality due to viruses. Model results were however relatively insensitive to this parameterisation, although the potential importance of viruses in marine systems should not be underestimated (Bratbak, 1993, 1996; Danovaro et al., 2011).

It has long been recognised that the parameterisation and functional form of zooplankton mortality, the model closure term, can have a pronounced effect on modelled ecosystem dynamics (e.g. Steele and Henderson, 1981, 1992, 1995; Murray and Parslow, 1999; Edwards and Yool, 2000; Fulton et al., 2003a, b; Neubert et al., 2004). Quadratic closure is a common choice, although other non-linear functional forms are also in use. While it is commonly stated that quadratic closure is dynamically stabilising, i.e. it prevents both blooms and extinction of prey, there is a limit to this influence (Edwards and Yool, 2000) since other processes can come into play. In our case, it is obvious that quadratic closure had a stabilising effect on the model. Its removal caused the bloom peak to be higher and also post-bloom phytoplankton levels to decline to near zero.

In contrast to the community's broad recognition of the potential sensitivity to choice of closure scheme, far less attention has been paid to model sensitivity regarding the fate of zooplankton mortality. In reality, there are likely various types of zooplankton mortality including grazing by higher predators, starvation and disease. As a mathematical closure term, one can consider the grazing loss to be partitioned between an infinite series of higher predators (e.g. Fasham et al., 1990), with partitioning between detritus and dissolved nutrients in both organic and inorganic form. The fate of these losses will occur with time delays and potentially also with spatial separation due to migration of predators. Moreover, any detrital production by higher predators would comprise significantly larger "particles" than those due to plankton death and would therefore be associated with much higher sinking rates. Non-grazing mortality might lead to production of detritus in situ. There is no consensus on best practice, despite the fact that different approaches to partitioning of zooplankton losses between detritus, nutrient and DOM differs markedly between models and can have a significant effect on modelled ecosystem function (Anderson et al., 2013). Future structural sensitivity studies should be con- ducted to explore how the $f$ ratio (the fraction of primary production fuelled by external nutrient) and $e$ ratio (i.e. relative export to total primary production) are affected by the various assumptions relating to zooplankton mortality and model closure.

Model sensitivity to choice of functional forms and parameterisation, often manifested as surprising and unforseen emergent predictions, is classic complexity science (BarYam, 1997). Understanding emergence and the consequences for accuracy of prediction is a key component of modelling complex systems (Anderson, 2005). Results here, as discussed above, showed varying sensitivities to different formulations and assumptions and demonstrated the utility of EMPOWER in tackling this important topic. High sensitivities have previously been documented in marine ecosystem models, e.g. to the exact form of the zooplankton functional response (Anderson, 2010; Wollrab and Diehl, 2015) and choice of zooplankton trophic transfer formulation (Anderson et al., 2013). Other studies have also shown "alarming" sensitivity to apparently small changes in the specification of biological models (e.g. Wood and Thomas, 1999; Fussmann and Blasius, 2005). Anderson (2005) described this insidious problem, namely sensitivity of emergent outcomes to interacting non-linear differential equations, as "all in the interactions". Dealing with it poses an ongoing challenge for the modelling community.

EMPOWER-1.0 is provided as a testbed which is suitable for examining the performance of any chosen marine ecosystem model, simple or complex. We chose to demonstrate its use by incorporating a simple NPZD ecosystem model. Simple marine ecosystem models are, however, all too often brushed aside in marine science today. While our objective here is not to delve deeply into the ongoing debate about complexity in models (e.g. Fulton et al., 2004; Anderson, 2005; Friedrichs et al., 2007; Ward et al., 2010), we would nevertheless like to comment on the worth of simple ecosystem models. Complex ecosystem models are often favoured today (e.g. Blackford et al., 2004; Moore et al., 2004; Le Quere et al., 2005) with a similar trend in ocean physics toward large, computationally demanding models. Many publications in recent years have involved the use of 3-D models (e.g. Le Quéré et al., 2005; Wiggert et al., 2006; Follows et al., 2007; Hashioka et al., 2013; Yool et al., 2013b; Vallina et al., 2014), although 1-D models are also well represented (e.g. Vallina et al., 2008; Kearney et al., 2012; Ward et al., 2013). The caveat is that improvements in prediction can only be achieved if the processes of interest can be adequately parameterised (Anderson, 2005). That is a big caveat and one made harder to achieve because it is often difficult and/or time consuming to thoroughly test the formulations and parameterisations involved. Simple NPZD-type models have a useful role in this regard. Albeit with tuning (but the complex models are tuned also), our NPZD model was successfully used to describe the seasonal cycles of phytoplankton and nutrients at four contrasting sites in the world ocean. 
It was readily applied to test different parameterisations for photosynthesis and mortality. At least in terms of basic bulk properties, simple models produce realistic predictions and are easy to thoroughly investigate and assess. The whole issue of model complexity ought in any case to be question dependent (Anderson, 2010), e.g. simple models may be useful to address questions on biogeochemical cycles whereas more complex models may be necessary to answer more ecologically relevant questions such as the effect of biodiversity on ecosystem function. The use of the EMPOWER testbed allows the user to investigate and determine whether a particular ecosystem model is sufficiently complex, or indeed too complex, to address the question of interest.

We have described the utility of slab models as a testbed underpinning marine ecosystem modelling research. This is however by no means their only use. Slab models are ideal for teaching ecological modelling. They embrace the complex interplay between primary production and the physicochemical environment, combined with top-down control by zooplankton. Students often have difficulty grasping the relative significance of causal effects in ecosystems (Grotzer and Basca, 2003), e.g. the relative roles of bottom-up versus top-down processes in structuring food webs. A certain amount of lecture material is of course needed, but there is no substitute for hands-on modelling providing an interactive approach whereby students can actively investigate ideas and interact between themselves and a teacher (Knapp and D'Avanzo, 2010). Insight can be gained by getting students to try simple things like switching grazing off, doubling phytoplankton growth rates, etc. The slab modelling framework provided herein is ideal for this purpose. The code is transparent, modular and readily adjusted to include alternate parameterisations, it is easily set up for alternate ocean sites, the model runs fast with graphs of results appearing on the screen on completion, results are readily written to output files for more in depth analysis and, by coding in R, the models can be accessed and run without need for purchasing proprietary software.

Finally, the great advances in marine ecology that the pioneers of plankton modelling achieved using slab models should not be forgotten. Riley, Steele and Fasham laid the foundations of today's marine ecosystem modelling using plankton models embedded within simple physics. Even in the modern arena, this use of simple physics cannot be dismissed as being too simple for practical application and there is no reason why further scientific advances cannot be made using slab models. Models are, fundamentally, all about simplifying reality. 


\section{Appendix A: Irradiance calculations}

Both the Evans and Parslow (1985) and Anderson (1993) subroutines for calculating daily photosynthesis require noon irradiance and day length as inputs. When there are data available, these data can be used as forcing for a model, akin to what is done for temperature. However, most typically light data is not available and so a light submodel must be used to prescribe the necessary forcing. A climatological approach is often used whereby these inputs are specified using trigonometric/astronomical equations. This task is not as straightforward as it might first appear. The basic equations are presented in texts such as Brock (1981) and Iqbal (1983). Some adjustments were provided by Shine (1984) and we use the equation for short-wave irradiance at the ocean surface on a clear day published therein:

$$
I_{\text {clear }}=\frac{I_{\mathrm{SC}} \cos ^{2}(z) / R_{v}^{2}}{1.2 \cos (z)+e_{0}(1.0+\cos (z)) / 1000+0.0455} .
$$

$I_{\mathrm{SC}}$ is the solar constant (e.g. $1368 \mathrm{~W} \mathrm{~m}^{-2}$ : Thekaekara and Drummond, 1971), i.e. the incoming solar radiation that would be incident on a perpendicular plane, immediately outside the atmosphere. $I_{\text {clear }}$ also depends on solar zenith angle $(z)$, Earth's radius vector $\left(R_{V}\right.$ : accounts for the eccentricity of the earth's orbit) and water vapour pressure $\left(e_{0}\right.$; the partial pressure of water vapour in the atmosphere). A typical value for $e_{0}$ is $12 \mathrm{mb}$ (e.g. Josey et al., 2003); the calculation of $I_{\text {clear }}$ is not sensitive to this parameter. The equation for $R_{V}$ is

$R_{V}=1 /(1+0.033 \cos (2 \pi J / 365))^{1 / 2}$,

where $J$ is day of year (Julian day; i.e. $1=1$ January). Solar zenith angle depends on latitude $(\varphi)$, solar declination angle $(\delta)$ and time of day $\left(\gamma\right.$, where the Earth moves $15^{\circ}$ per hour and $\gamma$ is difference from noon):

$\cos (z)=\sin (\varphi) \sin (\delta)+\cos (\varphi) \cos (\delta) \cos (\gamma)$.

The $\cos (\gamma)$ term becomes irrelevant when considering noon irradiance. Solar declination angle is given by

$\delta=23.45 \sin (2 \pi(284+J) / 365)$,

where $h$ is hour angle which is the difference between the given time and noon (where $1 \mathrm{~h}$ is $15^{\circ}$ ). Note that $\delta$ is expressed in degrees in the above equation ( 1 radian $=$ $\left.180 / \pi^{\circ}\right)$.

The flux of photosynthetically active solar radiation just below the ocean surface at noon, $I_{\text {noon }}$, can now be calculated:

$I_{\text {noon }}=C_{\mathrm{FAC}} f_{\mathrm{PAR}}(1-\phi) I_{\text {clear }}$,

where $f_{\mathrm{PAR}}$ is the fraction of solar radiation that is PAR ( $\lambda$ between 400 and $700 \mathrm{~nm}$ ), $\phi$ is ocean albedo and $C_{\mathrm{FAC}}$ is the effect of clouds on atmospheric transmission. Parameters $f_{\mathrm{PAR}}$ and $\phi$ are relatively invariant with typical values of 0.43 for $f_{\text {PAR }}$ and 0.04 for $\phi$ (e.g. Fasham et al., 1990). Dealing with the effects of clouds is a problematic issue for modellers. Simple empirical approaches have been developed, two of the most popular being those of Reed (1977) and Smith and Dobson (1984). We have opted for the former in which $C_{\mathrm{FAC}}$ is a function of zenith angles (specified in degrees):

$C_{\mathrm{FAC}}=1-0.62 W / 8+0.0019(90-z)$,

where $W$ is cloud fraction in oktas. A value of $W=6$ was used for all four stations.

The equation for calculating day length $\left(D_{L}, \mathrm{~h}\right)$ is (Brock, 1981)

$D_{L}=\frac{2}{15} \arccos (-\tan (\varphi) \tan (\delta))$.

\section{Appendix B: Analytic integrals for photosynthesis with depth}

The average photosynthesis within a layer of depth $\mathrm{H}$ is

$\bar{V}_{P(H)}=\frac{1}{H} \int_{z=0}^{H} V_{P}(z) \mathrm{d} z$

where $V_{P}$ is photosynthesis as a function of light intensity (specified as the $P-I$ curve). Two $P-I$ curves were investigated using EMPOWER, a Smith function (Eq. 7) and an exponential function (Eq. 8). Analytic solutions to Eq. (B1) are provided here for each of these two $P-I$ curves. In both cases a Beer's law attenuation with depth is assumed (parameter $\left.k_{\mathrm{PAR}}\right)$, i.e. $I(z)=I(0) e^{-\mathrm{kPARz}}$, where $I(0)$ is the irradiance entering the layer from above.

\section{B1 Smith $P$-I curve}

By performing a change of variables such that $x=\alpha I(z)$, the integral above becomes

$\bar{V}_{P(H)}=\frac{-V_{P}^{\max }}{H} \int_{z=0}^{H} \frac{1}{\left(\left(V_{P}^{\max }\right)^{2}+x^{2}\right)^{1 / 2}} \mathrm{~d} x$.

This integral is solved analytically using a trigonometric transformation and then integration by parts, giving

$$
\bar{V}_{P(H)}=\frac{V_{P}^{\max }}{k_{\mathrm{PAR}} H} \ln \left(\frac{x_{0}+\left(\left(V_{P}^{\max }\right)^{2}+x_{0}^{2}\right)^{1 / 2}}{x_{H}+\left(\left(V_{P}^{\max }\right)^{2}+x_{H}^{2}\right)^{1 / 2}}\right),
$$

where $x_{0}$ is $x(z=0)$ and $x_{H}$ is $x(z=H)$. 


\section{B2 Exponential $P$ - $I$ curve}

In order to integrate Equation $\mathrm{B} 1$ using an exponential $P-I$ curve it is first useful to define (Platt et al., 1980)

$I_{*}^{z}=\frac{I_{z} \alpha}{V_{P}^{\max }}$.

The integration over depth is then (see Platt et al., 1990)

$\bar{V}_{P(H)}=\frac{V_{P}^{\max }}{k_{\mathrm{PAR}} H} \sum_{n=1}^{\infty} \frac{(-1)^{n+1}}{n . n !}\left(\left(I_{*}^{0}\right)^{n}-\left(I_{*}^{H}\right)^{n}\right)$.

For practical purposes, we used a maximum $n$ value of 16 .

\section{Appendix C: Special formulations for calculating daily photosynthesis}

\section{C1 Evans and Parslow (1985) photosynthesis calculation}

Evans and Parslow (1985) provide an algorithm for calculating daily depth-integrated photosynthesis with the assumptions of a Smith $P-I$ curve (Eq. 3), a triangular pattern of irradiance from sunrise to sunset and light extinction calculated with a single Beer's law coefficient (Eq. 9). The average daily rate of photosynthesis within the mixed layer is calculated as

$\bar{V}_{P(H, \tau)}=2 \int_{0}^{\tau} \frac{1}{H} \int_{0}^{M} V_{P}(I, z) \mathrm{d} z \mathrm{~d} t$,

where $t$, measured in days, is 0 at sunrise and $\tau$ at noon and $H$ is layer depth. Assuming a triangular pattern of irradiance about noon, Eq. (A3.1) can be recast as (Evans and Parslow, 1985)

$\bar{V}_{P(H, \tau)}=\frac{2 V_{P}^{\max }}{k_{\mathrm{PAR}} H} \int_{0}^{\tau} \int_{\beta 1}^{\beta 2} \frac{t \mathrm{~d} y \mathrm{~d} t}{y\left(y^{2}+t^{2}\right)^{1 / 2}}$,

$\beta_{1}=\frac{V_{P}^{\max } \tau}{\alpha I_{\text {noon }}}, \beta_{2}=\beta_{1} \exp \left(k_{\mathrm{PAR}} H\right)$.

$I_{\text {noon }}$ is the photosynthetically active radiation (PAR) just below the ocean surface at noon. This integral is solved as (Evans and Parslow, 1985)

$$
\begin{aligned}
& \bar{V}_{P(H, \tau)}=\frac{2 V_{P}^{\max }}{k_{\mathrm{PAR}} H}\left[f\left(\beta_{2, \tau}\right)-f\left(\beta_{1, \tau)}\right.\right. \\
& -f\left(\beta_{2,0)}+f\left(\beta_{1}, 0\right)\right], \\
& f(y, t)=\left(y^{2}+t^{2}\right)^{1 / 2}-t \ln \frac{t+\left(y^{2}+t^{2}\right)^{1 / 2}}{y} .
\end{aligned}
$$

\section{C2 Anderson (1993) photosynthesis calculation}

The subroutine of Anderson (1993) was developed as an empirical approximation to the spectrally resolved model of light attenuation and photosynthesis of Morel (1988), used in combination with the polynomial method of integrating daily photosynthesis of Platt et al. (1990). It is based on an exponential $P-I$ curve (Eq. 8 ) and assumes a sinusoidal pattern of irradiance throughout the day, with the calculation of light attenuation using a piecewise Beer's law (Eq. 10). The irradiance leaving the base of each layer is

$I_{\text {base }, i}=I_{\text {base }, i-1} \exp \left[-k_{\mathrm{PAR}, i}\left(z_{\text {base }, i}-z_{\text {base }, i-1}\right)\right]$,

where $I_{\mathrm{base}, 0}$ is the irradiance immediately below the ocean surface and $z_{\text {base }, i}$ is the depth of the base of the layer $i$ (where $z_{\text {base }, 0}=0$ ).

The subroutine of Anderson (1993) also takes account of the fact that, in reality, $\alpha$ (the initial slope of the $P-I$ curve) depends on the spectral properties of light and therefore varies with depth in the water column. This parameter is the product of photosynthetic absorption cross section $a_{\mathrm{c}}(\lambda)$, which is spectrally dependent ( $\lambda$ denotes wavelength), and quantum yield $\varphi_{A}$ (Platt and Jassby, 1976; Platt, 1986):

$\alpha(\lambda)=a_{\mathrm{c}}(\lambda) \varphi_{A}$

Ordinarily (e.g. Table 2), $\alpha$ is presented as the initial slope of the $P-I$ curve for white light (i.e. spectral distribution as for irradiance at the ocean surface). The corresponding value of $\alpha$ for the wavelength at which absorption is maximum, $\alpha_{\max }$, is (Anderson, 1993)

$\alpha_{\max }=2.602 \alpha$.

The value of $\alpha$ for any given wavelength of PAR, $\alpha(\lambda)$, is then

$\alpha(\lambda)=\alpha_{\max } a \cdot(\lambda)$,

where $a^{*}(\lambda)$ is the dimensionless chlorophyll absorption cross section for wavelength $\lambda$. An additional complication, however, is that $a^{*}(\lambda)$ only applies when irradiance is specified as a scalar flux (Morel, 1991). Irradiance in the model is a downwelling flux and so Anderson (1993) converted between the two by defining a new version of the chlorophyll absorption cross section (which can be used in Eq. (C9) in place of $a^{*}(\lambda)$, in combination with downwelling irradiance):

$\alpha^{\#}(\lambda)=a^{*}(\lambda) k_{\mathrm{PAR}}(\lambda) / a_{c}(\lambda)$.

Again using the piecewise three-layer scheme described above for $k_{\mathrm{PAR}}$, an average value of $a^{\#}$ can be calculated for each layer by deriving an empirical approximation of Morel's (1988) full spectral model. As a first step, $a^{\#}$ at the ocean surface is calculated as

$a_{\text {base }, 0}^{\#}=h_{0}+h_{1} C^{1 / 2}+h_{2} C+h_{3} C^{3 / 2}+h_{4} C^{2}$, 
Table C1. Coefficients for use in the Anderson (1993) calculation of photosynthesis.

\begin{tabular}{lll}
\hline$h_{0}=0.36796$ & $h_{1}=0.17537$ & $h_{2}=-0.065276$ \\
$h_{3}=0.013528$ & $h_{4}=0.0011108$ & $g_{3}=-0.023074$ \\
$g_{1}=0.048014$ & $g_{2}=0.00023779$ & $g_{6}=0.0027974$ \\
$g_{4}=0.0031095$ & $g_{5}=-0.0090545$ & $g_{9}=0.0012398$ \\
$g_{7}=0.00085217$ & $g_{8}=-3.9804 \times 10^{-6}$ & $\Omega_{3}=0.028050$ \\
$\mathrm{~g}_{10}=-0.00061991$ & $\Omega_{2}=-0.28333$ & \\
$\Omega_{1}=1.9004$ & $\Omega_{5}=0.000030841$ & \\
$\Omega_{4}=-0.0014729$ & & \\
\hline
\end{tabular}

where the polynomial coefficients are given in Table $\mathrm{C} 1$. The $a^{\#}$ at the base of each layer and the average $a^{\#}$ in each layer are then calculated as

$a_{\mathrm{base}, i}^{\#}=\alpha_{\mathrm{base}, i-1}^{\#}+\alpha_{\mathrm{calc}, i}^{\#}$,

$a_{\mathrm{av}, i}^{\#}=\alpha_{\mathrm{base}, i-1}^{\#}+0.5 \alpha_{\mathrm{calc}, i}^{\#}$,

where $a_{\mathrm{calc}, i}^{\#}$ is a lengthy empirical calculation:

$a_{\text {calc }, i}^{\#}=f\left\{z_{\text {base }, i}\right\}-f\left\{z_{\text {base }, i-1}\right\}$,

$f\{z\}=(z+1)\left(g_{1}+g_{2} C^{1 / 2}+g_{5} C+g_{7} C^{3 / 2}\right)$

$+f_{1}\{z+1\}\left(g_{3}+g_{4} C^{1 / 2}+g_{9} C\right)$,

$+f_{2}\{z+1\}\left(g_{6}+g_{10} C\right)+f_{3}\{z+1\} g_{8}$

$f_{1}\{z+1\}=(z+1) \ln (z+1)-(z+1)$,

$f_{2}\{z+1\}=(z+1) \ln ^{2}(z+1)-2 f_{1}\{z+1\}$,

$f_{3}\{z+1\}=(z+1) \ln ^{3}(z+1)-3 f_{2}\{z+1\}$.

The coefficients, $g_{x}$, are provided in Table C1. With irradiance assumed to vary sinusoidally through the day, the average rate of photosynthesis within a layer $i$ is

$\bar{V}_{P(H, \tau)}=\frac{D V_{P}^{\max }}{24 H \pi k_{\mathrm{PAR}}} \sum_{j=1}^{5} \Omega_{j}\left(V_{1}^{j}-V_{2}^{j}\right)$,

$V_{1}=\alpha_{\max } a_{\mathrm{av}, i}^{\#} I_{\mathrm{base}, i-1} / V_{P}^{\max }$,

$V_{2}=\alpha_{\max } a_{\mathrm{av}, i}^{\#} I_{\mathrm{base}, i} / V_{P}^{\max }$,

where $D$ is day length (hours) and $\Omega_{j}$ are the polynomial coefficients (Platt et al., 1990; Table C1).

\section{Appendix D: EMPOWER1.0 user guide}

1. Installation and setup. The $\mathrm{R}$ programming language is freeware and is readily downloaded from the Internet for use on personal computers. For example, visit page http://www.r-project.org/. After installation, set up a directory to hold the model code and associated input and output files. We recommend also downloading an $\mathrm{R}$ editor, e.g, Tinn-R (also freeware).

2. Running R. Open the R console. From the toolbar, select "File" and "Change dir ..." and select the directory in which the model code and input files have been placed. To run the model, type: source(“EMPOWER1.R”)

3. Preparation of input files. The model reads in three input files, each as ASCII text files.

i. File NPZD_parms.txt. This file includes a single line header and then lists the value of each model parameter in turn, followed by a text string for the purpose of annotation. When changing the parameter list in the model, the corresponding section in the $\mathrm{R}$ code must be altered accordingly.

ii. File NPZD_extra.txt. This file holds initial values for state variables, additional parameters, and various flags: choice of station, choices for photosynthesis calculations ( $P-I$ curve, light attenuation, etc.) and grazing formulation. The user is at liberty to add to or remove from this list of flags as is desired. This file also contains flags for core model functions: run duration, time step, output type (none, last year, whole simulation), output frequency and integration method (Euler or Runge Kutta). These latter functions are required by the core code and should not be removed from this file.

iii. File stations_forcing.txt. This file has a header line for information and then holds monthly values for forcing, in our case mixed layer depth and temperature, for each station. There are 13 entries in each case, the first and last being the same and corresponding to the beginning and end of the year. A 366 unit array is set up in the model code for each forcing variable, with unit 1 corresponding to $t=0$, and linear interpolation carried out on the monthly values to fill each array.

4. Output files. These are generated automatically by the model, on completion of each model simulation. The type of output generated is controlled by flags (above). The output files are ASCII, comma separated and do not have headers. They are readily imported into various software packages, e.g. Microsoft Excel, for further analysis. The files are the following.

i. File out_statevars.txt. Outputs the state variables, ordered as they are in array $\mathrm{X}$ in the code. 
ii. File out_fluxes.txt. Outputs the model fluxes, ordered as they are in matrix flux $(i, j)$ in function FNget_flux. Thus, each line (corresponding to a point in time for output) has Nsvar*nfluxmax entries where Nsvar is the number of state variables in the model and nfluxmax is the maximum number of fluxes per state variable.

iii. File out_aux.txt. This file stores the values of auxiliary variables, as defined by the user in array Y (final section of function FNget_flux). The maximum size of this array is set by variable $\mathrm{nDvar}$.

5. Altering the model structure. If the user wants to change the number of state variables, nDvar or nfluxmax (above), adjustments should first be made to the short section of code "Variables specific to model: adjust accordingly". Alter nSvar, the initialisation of array $\mathrm{X}$ (which holds the state variables) and the text arrays Svarname and Svarnames (which are used for output). Then go to function FNget_flux and rewrite the line of code unpacking the state variables. Finally, specify the terms associated with the new state variable(s) in matrix flux $(i, j)$.

6. Altering model equations. The model equations are handled in function FNget_flux and can be adjusted as desired by the user, calling additional functions as necessary.

7. Graphical output. The model automatically generates graphical output on the computer screen on completion of each simulation. An advantage of $\mathrm{R}$ is that the syntax for generating plots is straightforward and the user should have no problem, working from the plots provided, in generating extra graphs as desired.

\section{Appendix E: Light attenuation in MEDUSA}

Light attenuation in the water column in the MEDUSA model (Yool et al., 2011, 2013a) is calculated assuming that PAR at the ocean surface can be divided equally into two wavebands, nominally red and green. The attenuation of each is calculated through the water column using Beer's law. The average light in a model layer can then be calculated on the basis of summing the two wavebands, this average is then used in combination with a $P-I$ curve to calculate photosynthesis. The extinction coefficients for red and green light, $x k r$ and $x k g$, are

$$
\begin{aligned}
& \mathrm{xkr}=\mathrm{xkr} 0+\mathrm{xkrp} \cdot \exp (\mathrm{x} \operatorname{lr} \ln (C)), \\
& \mathrm{xkg}=\mathrm{xkg} 0+\mathrm{xkgp} \cdot \exp (x \lg \cdot \ln (C)),
\end{aligned}
$$

where $C$ is chlorophyll $\left(\mathrm{mg} \mathrm{m}^{-3}\right)$. Values for the coefficients are $\mathrm{xkr} 0=0.225, \mathrm{xkrp}=0.037, \mathrm{xlr}=0.674, \mathrm{xkg} 0=0.0232$, $\mathrm{xkgp}=0.074$, and $\mathrm{xlg}=0.629$. 


\section{The Supplement related to this article is available online at doi:10.5194/gmd-8-2231-2015-supplement.}

Acknowledgements. T. R. Anderson and A. Yool acknowledge support from the Natural Environment Research Council, UK, as part of the Integrated Marine Biogeochemical Modelling Network to Support UK Earth System Research (i-MarNet) project (grant ref. NE/K001345/1). W. C. Gentleman acknowledges support from the Natural Sciences and Engineering Council of Canada. We wish to thank two anonymous referees for their critique of the manuscript.

Edited by: A. Ridgwell

\section{References}

Alderkamp, A.-C., Kulk, G., Buma, G. J., Visser, R. J. W., Van Dijken, G. L., Mills, M. M., and Arrigo, K. R.: The effect of iron limitation on photophysiology of Phaeocycstis Antarctica (Prymnesiophyceae) and Flagiariopsis cylindrus (Bacillariophyceae) under dynamic irradiance, J. Phycol., 8, 45-59, 2012.

Anderson, T. R.: A spectrally averaged model of light penetration and photosynthesis, Limnol. Oceanogr., 38, 1403-1419, 1993.

Anderson, T. R.: Relating C:N ratios in zooplankton food and faecal pellets using a biochemical model, J. Exp. Mar. Biol. Ecol., 184, 183-199, 1994.

Anderson, T. R.: Plankton functional type modelling: running before we can walk?, J. Plankton Res., 27, 1073-1081, 2005.

Anderson, T. R.: Progress in marine ecosystem modelling and the "unreasonable effectiveness of mathematics", J. Mar. Syst., 81, 4-11, 2010.

Anderson, T. R. and Gentleman, W. C.: The legacy of Gordon Arthur Riley (1911-1985) and the development of mathematical models in biological oceanography, J. Mar. Res., 70, 1-30, 2012.

Anderson, T. R. and Hessen, D. O.: Carbon or nitrogen limitation in marine copepods?, J. Plankton Res., 17, 317-331, 1995.

Anderson, T. R. and Mitra, A.: Dysfunctionality in ecosystem models: an underrated pitfall?, Prog. Oceanogr., 84, 66-68, 2010.

Anderson, T. R. and Pondaven, P.: Non-Redfield carbon and nitrogen cycling in the Sargasso Sea: pelagic imbalances and export flux, Deep-Sea Res. Pt. I, 50, 573-591, 2003.

Anderson, T. R., Gentleman, W. C., and Sinha, B.: Influence of grazing formulations on the emergent properties of a complex ecosystem model in a global general circulation model, Prog. Oceanogr., 87, 201-213, 2010.

Anderson, T. R., Hessen, D. O., Mitra, A., Mayor, D. J., and Yool, A.: Sensitivity of secondary production and export flux to choice of trophic transfer formulation in marine ecosystem models, J. Mar. Syst., 125, 41-53, 2013.

Anderson, T. R., Christian, J. R., and Flynn, K. J.: Modeling DOM biogeochemistry, in: Biogeochemistry of marine dissolved organic matter, 2nd Edn., edited by: Hansell, D. A. and Carlson, C. A., Academic Press, 635-667, 2014.
Antonov, J. I., Seidov, D., Boyer, T. P., Locarnini, R. A., Mishonov, A. V., Garcia, H. E., Baranova, O.K., Zweng, M. M., and Johnson, D. R.: World Ocean Atlas 2009, Volume 2: Salinity, edited by: Levitus, S., NOAA Atlas NESDIS 69, U.S. Government Printing Office, Washington, DC, 184 pp., 2010.

Arhonditsis, G. B., Adams-Vanharn, B. A., Nielsen, L., Stow, C. A., and Reckhow, K. H.: Evaluation of the current state of mechanistic aquatic biogeochemical modeling: Citation analysis and future perspectives, Environ. Sci. Technol., 40, 6547-6554, 2006.

Backhaus, J. O., Hegseth, E. N., Wehde, H., Irigoien, X., Hatten, K., and Logemann, K.: Convection and primary production in winter, Mar. Ecol. Prog. Ser., 251, 1-14, 2003.

Bar-Yam, U.: Dynamics of Complex Systems, Addison-Wesley, Reading, Massachusetts, 848 pp., 1997.

Boushaba, K. and Pascual, M.: Dynamics of the "echo" effect in a phytoplankton system with nitrogen fixers, Bull. Math. Biol., 67, 487-507, 2005.

Blackford, J. C., Allen, J. I., and Gilbert, F. J.: Ecosystem dynamics at six contrasting sites: a generic modelling study, J. Mar. Syst., 52, 191-215, 2004

Bouman, H. A., Platt, T., Kraay, G. W., Sathyendranath, S., and Irwin, B. D.: Bio-optical properties of the subtropical North Atlantic. I. Vertical variability, Mar. Ecol. Prog. Ser., 200, 3-18, 2000.

Bratbak, G., Egge, J. K., and Heldal, M.: Viral mortality of the marine alga Emiliania huxleyi (Haptophyceae) and termination of algal blooms, Mar. Ecol. Prog. Ser., 93, 39-48, 1993.

Bratbak, G., Willson, W., and Heldal, M.: Viral control of Emiliania huxleyi blooms?, J. Mar. Syst., 9, 75-81, 1996.

Brock, T. D.: Calculating solar radiation for ecological studies, Ecol. Modell., 14, 1-19, 1981.

Chai, F., Lindley, S. T., Toggweiler, J. R., and Barber, R. T.: Testing the importance of iron and grazing in the maintenance of the high nitrate condition in the equatorial Pacific Ocean, a physicalbiological model study, in: The Changing Ocean Carbon Cycle, edited by: Hanson, R. B., Ducklow, H. W., and Field, J. G., International Geosphere-Biosphere Programme (IGBP) Book Series 5. Cambridge University Press, Cambridge, 156-186, 2000.

Chuck, A., Tyrrell, T., Totterdell, I. J., and Holligan, P. M.: The oceanic response to carbon emissions over the next century: investigation using three ocean carbon cycle models, Tellus, 57B, 70-86, 2005.

Coale, K. H., Johnson, K.S., Fitzwater, S. E., Gordon, R. M., Tanner, S., Chavez, F. P., Ferioli, L., Sakamoto, C., Rogers, P., Millero, F., Steinberg, P., Nightingale, P., Cooper, D., Cochlan, W. P., Landry, M. R., Constantinou, J., Rollwagen, G., Trasvina, A., and Kudela, R.: A massive phytoplankton bloom induced by an ecosystem-scale iron fertilization experiment in the equatorial Pacific Ocean, Nature, 838, 495-501, 1996.

Cullen, J. J.: On models of growth and photosynthesis in phytoplankton, Deep-Sea Res., 37, 667-683, 1990.

Danovaro, R., Corinaldesi, C., Dell'Anno, A., Fuhrman, J. A., Middelburg, J. J., Noble, R. T. and Suttle, C. A.: Marine viruses and global climate change. FEMS Microbiol. Rev., 35, 933-1034, 2011.

Ducklow, H. W. and Harris, R. P.: Introduction to the JGOFS North Atlantic Bloom Experiment, Deep Sea Res. Pt. II, 40, 1-8, 1993.

Edwards, A. M. and Yool, A.: The role of higher predation in plankton population models, J. Plankton Res., 22, 1085-1112, 2000. 
Eppley, R. W.: Temperature and phytoplankton growth in the sea, Fish. Bull. Nat. Ocean Atmos. Adm., 70, 1063-1085, 1972.

Eppley, R. W. and Peterson, B. J.: Particulate organic matter flux and planktonic new production in the deep ocean, Nature, 282, 677-680, 1979.

Evans, G. T. and Parslow, J. S.: A model of annual plankton cycles, Biol. Oceanogr., 3, 327-347, 1985.

Fasham, M. J. R.: Modelling the marine biota, in: The Global Carbon Cycle, NATO ASI Series Vol. I15, edited by: Heimann, M., 457-504, 1993.

Fasham, M. J. R.: Variations in the seasonal cycle of biological production in subarctic oceans: A model sensitivity analysis, DeepSea Res. Pt. I, 42, 1111-1149, 1995.

Fasham, M. J. R. and Evans, G. T.: The use of optimization techniques to model marine ecosystem dynamics at the JGOFS station at $47^{\circ} \mathrm{N} 20^{\circ} \mathrm{W}$, Phil. Trans. R. Soc. Lond. B, 348, 203-209, 1995.

Fasham, M. J. R., Ducklow, H. W., and McKelvie, S. M.: A nitrogen-based model of plankton dynamics in the oceanic mixed layer, J. Mar. Res., 48, 591-639, 1990.

Fennel, K., Losch, M., Schröter, J., and Wenzel, M.: Testing a marine ecosystem model: sensitivity analysis and parameter optimization, J. Mar. Syst., 28, 45-63, 2001.

Findlay, H. S., Yool, A., Nodale, M., and Pitchford, J. W.: Modelling of autumn plankton bloom dynamics, J. Plankton Res., 28, 209220, 2006.

Fleming, R. H.: The control of diatom populations by grazing, J. Cons. Int. Expl. Mer., 14, 210-227, 1939.

Follows, M. J., Dutkiewicz, S., Grant, S., and Chisholm, S. W.: Emergent biogeography of microbial communities in a model ocean. Science, 315, 1843-1846, 2007.

Friedrichs, M. A. M., Dusenberry, J. A., Anderson, L. A., Armstrong, R. A., Chai, F., Christian, J. R., Doney, S. C., Dunne, J., Fujii, M., Hood, R., McGillicuddy, D. J., Moore, K. J., Schartau, M., Spitz and Y. H., Wiggert, J. D.: Assessment of skill and portability in regional marine biogeochemical models: Role of multiple planktonic groups, J. Geophys. Res., 112, C08001, doi:10.1029/2006JC003852, 2007.

Frost, B. W.: Grazing control of phytoplankton stock in the open subarctic Pacific Ocean: a model assessing the role of mesozooplankton, particularly the large calanoid copepods Neocalanus spp., Mar. Ecol. Prog. Ser., 39, 49-68, 1987.

Fulton, E. A., Smith, A. D. M., and Johnson, C. R.: Mortality and predation in ecosystem models: is it important how these are expressed?, Ecol. Model., 169, 157-178, 2003a.

Fulton, E. A., Smith, A. D. M., and Johnson, C. R.: Effect of complexity on marine ecosystem models, Mar. Ecol. Prog. Ser., 253, 1-16, 2003b.

Fulton, E. A., Parslow, J. S., Smith, A. D. M., and Johnson, C. R.: Biogeochemical marine ecosystem models II: the effect of physiological detail on model performance, Ecol. Model., 173, 371406, 2004

Fussmann, G. F. and Blasius, B.: Community response to enrichment is highly sensitive to model structure, Biol. Lett., 1, 9-12, 2005.

Garcia, H. E., Locarnini, R. A., Boyer, T. P., Antonov, J. I., Zweng, M. M., Baranova, O. K., and Johnson, D. R.: World ocean atlas 2009, volume 4: nutrients (phosphate, nitrate, silicate), in:
NOAA Atlas NESDIS 71, edited by: Levitus, S., US Government Printing Office, Washington, DC, 398 pp., 2010.

Gentleman, W.: A chronology of plankton dynamics in silico: how computer models have been used to study marine ecosystems, Hydrobiologia, 480, 69-85, 2002.

Gentleman, W., Leising, A., Frost, B., Strom, S., and Murray, J.: Functional responses for zooplankton feeding on multiple resources: a review of assumptions and biological dynamics, Deep Sea Res. Pt. II, 50, 2847-2875, 2003.

Gilbert, P. M., Allen, J. I., Artioli, Y., Beusen, A., Bouwman, L., Harle, J., Holmes, R., and Holt, J.: Vulnerability of coastal ecosystems to changes in harmful algal bloom distribution in response to climate change: projections based on model analysis, Global Change Biol., 20, 3845-3858, 2014.

Gran, H. H.: Phytoplankton. Methods and problems, J. Conseil Int. Expl. Mer., 7, 343-358, 1932.

Gran, H. H. and Braarud, T.: A quantitative study of the phytoplankton in the Bay of Fundy and the Gulf of Maine (including observations on hydrography, chemistry and turbidity), J. Biological Bd. Canada, 1, 279-433, 1935.

Grotzer, T. A. and Basca, B. B.: How does grasping the underlying causal structures of ecosystems impact students' understanding?, J. Biol. Educat., 38, 16-29, 2003.

Harrison, W. G. and Platt, T.: Photosynthesis-irradiance relationships in polar and temperate phytoplankton populations, Polar Biol., 5, 153-164, 1986.

Hashioka, T., Vogt, M., Yamanaka, Y., Le Quéré, C., Buitenhuis, E. T., Aita, M. N., Alvain, S., Bopp, L., Hirata, T., Lima, I., Sailley, S., and Doney, S. C.: Phytoplankton competition during the spring bloom in four plankton functional type models, Biogeosciences, 10, 6833-6850, doi:10.5194/bg-10-6833-2013, 2013.

Hemmings, J. C. P., Srokosz, M. A., Challenor, P., and Fasham, M. J. R.: Split-domain calibration of an ecosystem model using satellite ocean colour data, J. Mar. Syst., 50, 141-179, 2004.

Hinckley, S., Coyle, K. O., Gibson, G., Hermann, A. J., and Dobbins, E. L.: A biophysical NPZ model with iron for the Gulf of Alaska: Reproducing the differences between an oceanic HNLC ecosystem and a classical northern temperate shelf ecosystem, Deep Sea Res. Pt. II, 56, 2520-2536, 2009.

Holt, J., Allen, J. I., Anderson, T. R., Brewin, R., Butenschön, M., Harle, J., Huse, G., Lehodey, P., Lindemann, C., Memery, L., Salihoglu, B., Senina, I., and Yool, A.: Challenges in integrative approaches to modelling the marine ecosystems of the North Atlantic: Physics to fish and coasts to ocean. Prog. Oceanogr., 129, 285-313, 2014.

Huisman, J., Arrayas, M., Ebert, U., and Sommeijer, B.: How do sinking phytoplankton species manage to persist?, Am. Nat., 159, 245-254, 2002.

Huot, Y., Babin, M., and Bruyant, F.: Photosynthetic parameters in the Beaufort Sea in relation to the phytoplankton community structure, Biogeosciences, 10, 3445-3454, doi:10.5194/bg10-3445-2013, 2013.

Hurtt, G. C. and Armstrong, R. A.: A pelagic ecosystem model calibrated with BATS data, Deep-Sea Res., 43, 653-683, 1996.

Iqbal, M.: An Introduction to Solar Radiation. Academic Press, Toronto, 390 pp., 1983.

Josey, S. A., Pascal, R. W., Taylor, P. K., and Yelland, M. J.: A new formula for determining the atmospheric longwave flux at the 
ocean surface at mid-high latitudes, J. Geophys. Res., 108, 3108, doi:10.1029/2002JC001418, 2003.

Kawamiya, M., Kishi, M., Yamanaka, Y., and Suginohara, N.: An ecological-physical coupled model applied to Station Papa, J. Oceanogr., 51, 635-664, 1995.

Kearney, K. A., Stock, C., Aydin, K., and Sarmiento, J. L.: Coupling planktonic ecosystem and fisheries food web models for a pelagic ecosystem: Description and validation for the subarctic Pacific, Ecol. Modell., 237-238, 43-62, 2012.

Kidston, M., Matear, R., and Baird, M. E.: Phytoplankton growth in the Australian sector of the Southern Ocean, examined by optimising ecosystem model parameters, J. Mar. Syst., 128, 123$137,2013$.

Kimball, H. H.: Amount of solar radiation that reaches the surface of the earth on the land and on the sea, and methods by which it is measured, Mon. Weather Rev., 56, 393-398, 1928.

Knapp, A. K. and D'Avanzo, C.: Teaching with principles: toward more effective pedagogy in ecology, Ecosphere, 1, 1-10, 2010.

Kwiatkowski, L., Yool, A., Allen, J. I., Anderson, T. R., Barciela, R., Buitenhuis, E. T., Butenschön, M., Enright, C., Halloran, P. R., Le Quéré, C., de Mora, L., Racault, M.-F., Sinha, B., Totterdell, I. J., and Cox, P. M.: iMarNet: an ocean biogeochemistry model intercomparison project within a common physical ocean modelling framework, Biogeosciences, 11, 7291-7304, doi:10.5194/bg-11-7291-2014, 2014.

Landry, M. R., Barber, R. T., Bidigare, R. R., Chai, F., Coale, K. H., Dam, H. G., Lewis, M. R., Lindley, S. T., McCarthy, J. J., Roman, M. R., Stoecker, D. K., Verity, P. G., and White, J. R.: Iron and grazing constraints on primary production in the central equatorial Pacific: An EqPac synthesis, Limnol. Oceanogr., 42, 405-418, 1997.

Landry, M. R., Selph, K. E., Taylor, A. G., Décima, M., Balch, W. M., and Bidigare, R. R.: Phytoplankton growth, grazing and production balances in the HNLC equatorial Pacific, Deep Sea Res. Pt. II, 58, 524-535, 2011.

Le Quéré, C., Harrison, S. P., Prentice, I. C., Buitenhuis, E. T., Aumont, O., Bopp, L., Claustre, H., Cotrim Da Cunha, L., Geider, R., Giraud, X., Klaas, C., Kohfeld, K. E., Legendre, L., Manizza, M., Platt, T., Rivkin, R. B., Sathyendranath, S., Uitz, J., Watson, A. J., and Wolf-Gladrow, D.: Ecosystem dynamics based on plankton functional types for global ocean biogeochemistry models, Global Change Biol., 11, 2016-2040, 2005.

Levy, M., Klein, P., and Treguier, A.-M.: Impacts of sub-mesoscale physics on phytoplankton production and subduction, J. Mar. Res., 59, 535-565, 2001.

Lewis, K. and Allen, J. I.: Validation of a hydrodynamic-ecosystem model simulation with time-series data collected in the western English Channel, J. Mar. Syst., 77, 296-311, 2009.

Lewis, K., Allen, J. I., Richardson, A. J., and Holt, J. T.: Error quantification of a high resolution coupled hydrodynamic-ecosystem coastal-ocean model: Part3, validation with continuous plankton recorder data, J. Mar. Syst., 63, 209-224, 2006.

Llebot, C., Spitz, Y. H., Solé, J., and Estrada, M.: The role of inorganic nutrients and dissolved organic phosphorus in the phytoplankton dynamics of a Mediterranean bay. A modeling study, J. Mar. Syst., 83, 192-208, 2010.

Locarnini, R. A., Mishonov, A. V., Antonov, J. I., Boyer, T. P., Garcia, H. E., Baranova, O. K., Zweng, M. M., and Johnson, D. R.: World Ocean Atlas 2009, Volume 1: Temperature, edited by:
Levitus, S., NOAA Atlas NESDIS 68, U.S. Government Printing Office, Washington, DC, 184 pp., 2010.

Lochte, K., Ducklow, H. W., Fasham, M. J. R., and Stienen, C.: Plankton succession and carbon cycling at $47^{\circ} \mathrm{N} 20^{\circ} \mathrm{W}$ during the JGOFS North Atlantic Bloom Experiment, Deep Sea. Res. Pt. II, 40, 91-114, 1993.

Mayor, D. J., Cook, K., Thornton, B., Walsham, P., Witte, U. F. M., Zuur, A. F., and Anderson, T. R.: Absorption efficiencies and basal turnover of $\mathrm{C}, \mathrm{N}$ and fatty acids in a marine Calanoid copepod, Funct. Ecol., 25, 509-518, 2011.

Marañón, E. and Holligan, P.M.: Photosynthetic parameters of phytoplankton from $50^{\circ} \mathrm{N}$ to $50^{\circ} \mathrm{S}$ in the Atlantic Ocean. Mar. Ecol. Prog. Ser., 176, 191-203, 1999.

Martin, J. H. and IronEx team: Testing the iron hypothesis in ecosystems of the equatorial Pacific Ocean, Nature, 371, 123129, 1994.

Matear, R. J.: Parameter optimization and analysis of ecosystem models using simulated annealing: A case study at Station P, J. Mar. Res., 53, 571-607, 1995.

Mitra, A.: Are closure terms appropriate or necessary descriptors of zooplankton loss in nutrient-phytoplankton-zooplankton type models?, Ecol. Model., 220, 611-620, 2009.

Mitra, A., Flynn, K. J., and Fasham, M. J. R.: Accounting for grazing dynamics in nitrogen-phytoplankton-zooplankton models, Limnol. Oceanogr., 52, 649-661, 2007.

Mitra, A., Castellani, C., Gentleman, W. C., Jónasdóttir, S. H., Flynn, K. J., Bode, A., Halsband, C., Kuhn, P., Licandro, P., Agersted, M. D., Calbet, A., Lindeque, P. K., Koppelmann, R., Møller, E. F., Gislason, A., Nielsen, T. G., and St John, M.: Bridging the gap between marine biogeochemical and fisheries sciences; configuring the zooplankton link, Prog. Oceanogr., 129, 176-199, 2014.

Mongin, M., Nelson, D. M., Pondaven, P., and Tréguer, P.: Simulation of upper-ocean biogeochemistry with a flexible-composition phytoplankton model: $\mathrm{C}, \mathrm{N}$ and $\mathrm{Si}$ cycling and Fe limitation in the Southern Ocean, Deep-Sea Res. Pt. II, 53, 601-619, 2006.

Moore, K. J., Doney, S. C., and Lindsay, K.: Upper ocean ecosystem dynamics and iron cycling in a global threedimensional model, Global Biogeochem. Cy., 18, GB4028, doi:10.1029/2004GB002220, 2004.

Morel, A.: Optical modelling of the upper ocean in relation to its biogenous matter content (case 1 waters), J. Geophys. Res., 93, 10749-10768, 1988.

Morel, A.: Light and marine photosynthesis: a spectral model with geochemical and climatological implications, Prog. Oceanogr., 26, 263-306, 1991.

Murray, A. G. and Parslow, J. S.: The analysis of alternative formulations in a simple model of a coastal ecosystem, Ecol. Model., 119, 149-166, 1999.

Natvik, L.-J., Eknes, M., and Evensen, G.: A weak constraint inverse for a zero-dimensional marine ecosystem model, J. Mar. Syst., 28, 19-44, 2001.

Neubert, M. G., Klanjscek, T., and Caswell, H.: Reactivity and transient dynamics of predator-prey and food web models, Ecol. Model., 179, 29-38, 2004.

Onitsuka, G. and Yanagi, T.: Differences in ecosystem dynamics between the northern and southern parts of the Japan Sea: Analyses with two ecosystem models, J. Oceanogr., 61, 415-433, 2005. 
O’Reilly, J. E., Maritorena, S., Mitchell, B. G., Siegal, D. A., Carder, K. L., Garver, S. A., Kahru, M., and McClain, C.: Ocean color chlorophyll algorithms for SeaWiFS, J. Geophys. Res., 103, 24937-24953, 1998.

Oschlies, A. and Garçon, V.: An eddy-permitting coupled physicalbiological model of the North Atlantic 1 . Sensitivity to advection numerics and mixed layer physics, Global Biogeochem. Cy., 13, 135-160, 1999.

Oschlies, A. and Schartau, M.: Basin-scale performance of a locally optimized marine ecosystem model, J. Mar. Res., 63, 335-358, 2005

Platt, T.: Primary production of the ocean water column as a function of surface light intensity algorithms for remote sensing, Deep-Sea Res., 33, 149-163, 1986.

Platt, T. and Jassby, A. D.: The relationship between photosynthesis and light for natural assemblages of coastal marine phytoplankton, J. Phycol., 12, 421-430, 1976.

Platt, T., Gallegos, C. L., and Harrison, W. G.: Photoinhibition of photosynthesis in natural assemblages in marine phytoplankton, J. Mar. Res., 38, 687-701, 1980.

Platt, T., Sathyendranath, S., and Ravindran, P.: Primary production by phytoplankton: Analytic solutions for daily rates per unit area of water surface, Proc. R. Soc. Lond. Ser. B, 241, 101-111, 1990.

Popova, E. E., Fasham, M. J. R., Osipov, A. V., and Ryabchenko, V. A.: Chaotic behaviour of an ocean ecosystem model under seasonal external forcing, J. Plankton Res., 19, 1495-1515, 1997.

Price, N. M., Ahner, B. A., and Morel, F. M. M.: The equatorial Pacific: Grazer controlled phytoplankton populations in an ironlimited ecosystem, Limnol. Oceanogr., 39, 520-534, 1994.

Record, N. R., Pershing, A. J., Runge, J. A., Mayo, C. A., Monger, B. C., and Chen, C.: Improving ecological forecasts of copepod community dynamics using genetic algorithms, J. Mar. Syst., 82, 96-110, 2010.

Reed, R. K.: On estimating insolation over the ocean, J. Phys. Oceanogr., 7, 482-485, 1977.

Rey, F.: Photosynthesis-irradiance relationships in natural phytoplankton populations of the Barents Sea, Polar Res., 10, 105116, 1991.

Riley, G. A.: Factors controlling phytoplankton populations on Georges Bank, J. Mar. Res., 6, 54-73, 1946.

Riley, G. A., Stommel, H., and Bumpus, D. F.: Quantitative ecology of the plankton of the western North Atlantic, Bull. Bingham Oceanogr. Coll., 12, 1-169, 1949.

Riley, J. S., Sanders, R., Marsay, C., Le Moigne, F. A. C., Achterberg, E. P., and Poulton, A. J.: The relative contribution of fast and slow sinking particles to ocean carbon export, Global Biogeochem. Cy., 26, GB1026, doi:10.1029/2011GB004085, 2012.

Robinson, C. L. K., Ware, D. M., and Parsons, T. R.: Simulated annual plankton production in the northeastern Pacific coastal upwelling domain, J. Plankton Res., 15, 161-183, 1993.

Rykiel Jr., E. J.: Testing ecological models: the meaning of validation, Ecol. Modell., 90, 229-244, 1996.

Salihoglu, B., Garçon, V., Oschlies, A., and Lomas, M. W.: Influence of nutrient utilization and remineralization stoichiometry on phytoplankton species and carbon export: A modeling study at BATS. Deep-Sea Res. Pt. I, 55, 73-107, 2008.

Sathyendranath, S., Stuart, V., Nair, A., Oka, K., Nakane, T., Bouman, H., Forget, M.-H., Maass, H., and Platt, T.: Carbon- to-chlorophyll ratio and growth rate of phytoplankton in the sea, Mar. Ecol. Prog. Ser., 383, 73-84, 2009.

Schartau, M., Oschlies, A., and Willebrand, J.: Parameter estimates of a zero-dimensional ecosystem model applying the adjoint method, Deep-Sea Res. Pt. II, 48, 1769-1800, 2001.

Shine, K. P.: Parametrization of the shortwave flux over high albedo surfaces as a function of cloud thickness and surface albedo, Q. J. Roy. Meteorol. Soc., 110, 747-764, 1984.

Slezak, D. F., Suárez, C., Cecchi, G. A., Marshall, G., and Stolovitzky, G.: When the optimal is not the best: Parameter estimation in complex biological models, Plos ONE, 5, 1-10, 2010.

Smith, S. D. and Dobson, F. E.: The heat budget at Ocean Weather Ship Bravo, Atmos.-Ocean., 22, 1-22, 1984.

Smith Jr., W. O. and Lancelot, C.: Bottom-up versus top-down control in phytoplankton of the Southern Ocean, Antarctic Sci., 16, 531-539, 2004.

Soetaert, K., Petzoldt, T., and Woodrow, S.: Solving differential equations in R, The R Journal, 2, 5-15, 2010.

Spitz, Y. H., Moisan, J. R., Abbott, M. R., and Richman, J. G.: Data assimilation and a pelagic ecosystem model: parameterization using time series observations, J. Mar. Syst., 16, 51-68, 1998.

Spitz, Y. H., Moisan, J. R., and Abbott, M. R.: Configuring an ecosystem model using data from the Bermuda Atlantic Time Series (BATS), Deep-Sea Res. Pt. II, 48, 1733-1768, 2001.

Steele, J. H.: Plant production on the Fladen Ground, J. Mar. Biol Ass. UK, 35, 1-33, 1956.

Steele, J. H.: Plant production in the northern North Sea, Scottish Home Dept., Mar. Res., 1958, 1-36, 1958.

Steele, J. H.: Environmental control of photosynthesis in the sea, Limnol. Oceanogr., 7, 137-150, 1962.

Steele, J. H.: The Structure of Marine Ecosystems, Harvard Univ. Press, 128 pp., 1974.

Steele, J. H.: Prediction, scenarios and insight: The uses of an endto-end model, Prog. Oceanogr., 102, 67-73, 2012.

Steele, J. H. and Henderson, E. W.: A simple plankton model, Am. Nat., 117, 676-691, 1981.

Steele, J. H. and Henderson, E. W.: The role of predation in plankton models, J. Plankton Res., 14, 157-172, 1992.

Steele, J. H. and Henderson, E. W.: The significance of interannual variability. In: Towards a Model of Ocean Biogeochemical Processes, edited by: Evans, G. T. and Fasham, M. J. R., Springer Verlag, Heidelberg, 237-360, 1993.

Steele, J. H. and Henderson, E. W.: Predation control of plankton demography, ICES J. Mar. Sci., 52, 565-573, 1995.

Straile, D.: Gross growth efficiencies of protozoan and metazoan zooplankton and their dependence on food concentration, predator-prey weight ratio, and taxonomic group, Limnol. Oceanogr., 42, 1375-1385, 1997.

Thekaekara, M. P. and Drummond, A. J.: Standard values for the solar constant and its spectral components, Nature, 229, 6-9, 1971

Tsang, C.-F.: The modeling process and model validation, Ground Water, 29, 825-831, 1991.

Tyrrell, T.: The relative influences of nitrogen and phosphorus on oceanic primary production, Nature, 400, 525-531, 1999.

Vallina, S. M., Simó, R., Anderson, T. R., Gabric, A., Cropp, R., and Pacheco, J. M.: A dynamic model of oceanic sulfur (DMOS) applied to the Sargasso Sea: Simulating the dimethyl- 
sulfide (DMS) summer paradox, J. Geophys. Res., 113, G01009, doi:10.1029/2007JG000415, 2008.

Vallina, S. M., Ward, B. A., Dutkiewicz, S., and Follows, M. J.: Maximal feeding with active prey-switching: A kill-the-winner functional response and its effect on global diversity and biogeography, Prog. Oceanogr., 120, 93-109, 2014.

Ward, B. A. and Waniek, J. J.: Phytoplankton growth conditions during autumn and winter in the Irminger Sea, North Atlantic, Mar. Ecol. Prog. Ser., 334, 47-61, 2007.

Ward, B. A., Friedrichs, M. A. M., Anderson, T. R., and Oschlies, A: Parameter optimisation techniques and the problem of underdetermination in marine biogeochemical models, J. Mar. Syst., 81, 34-43, 2010.

Ward, B. A., Schartau, M., Oschlies, A., Martin, A. P., Follows, M. J., and Anderson, T. R.: When is a biogeochemical model too complex? Objective model reduction and selection for North Atlantic time-series sites, Prog. Oceanogr., 116, 49-65, 2013.

Weinbauer, M. G.: Ecology of prokaryotic viruses, FEMS Microb. Rev., 28, 127-181, 2004.

Wiggert, J. D., Murtugudde, R. G., and Christian, J. R.: Annual ecosystem variability in the tropical Indian Ocean: Results of a coupled bio-physical ocean general circulation model. Deep-Sea Res. Pt. II, 53, 644-676, 2006.

Wilson, S. E., Steinberg, D. K., and Buesseler, K. O.: Changes in fecal pellet characteristics with depth as indicators of zooplankton repackaging of particles in the mesopelagic zone of the subtropical and subarctic North Pacific Ocean, Deep-Sea Res. Pt. II, 55, 1636-1647, doi:10.1016/j.dsr2.2008.04.019, 2008.
Wollrab, S. and Diehl, S.: Bottom-up responses of the lower oceanic food web are sensitive to copepod mortality and feeding behaviour, Limnol. Oceanogr., 60, 641-656, 2015.

Wood, S. N. and Thomas, M. B.: Super-sensitivity to structure in biological models. Proc. Roy. Soc. Lond. B, 266, 565-570, 1999.

Xiao, Y. and Friedrichs, M. A. M.: Using biogeochemical data assimilation to assess the relative skill of multiple ecosystem models in the Mid-Atlantic Bight: effects of increasing the complexity of the planktonic food web, Biogeosciences, 11, 3015-3030, doi:10.5194/bg-11-3015-2014, 2014.

Ye, Y., Völker, C., Bracher, A., Taylor, B., and Wolf-Gladrwo, D. A.: Environmental controls on $\mathrm{N}_{2}$ fixation by Trichodesmium in the tropical eastern North Atlantic Ocean - A model-based study, Deep Sea Res. Pt. I, 64, 104-117, 2012.

Yool, A., Popova, E. E., and Anderson, T. R.: Medusa-1.0: a new intermediate complexity plankton ecosystem model for the global domain, Geosci. Model Dev., 4, 381-417, doi:10.5194/gmd-4381-2011, 2011.

Yool, A., Popova, E. E., and Anderson, T. R.: MEDUSA-2.0: an intermediate complexity biogeochemical model of the marine carbon cycle for climate change and ocean acidification studies, Geosci. Model Dev., 6, 1767-1811, doi:10.5194/gmd-6-17672013, 2013a.

Yool, A., Popova, E. E., Coward, A. C., Bernie, D., and Anderson, T. R.: Climate change and ocean acidification impacts on lower trophic levels and the export of organic carbon to the deep ocean, Biogeosciences, 10, 5831-5854, doi:10.5194/bg-10-5831-2013, 2013b. 